\title{
Mechanical Performance versus Corrosion Damage Indicators for Corroded Steel Reinforcing Bars
}

\author{
Silvia Caprili, ${ }^{1}$ Jörg Moersch, ${ }^{2}$ and Walter Salvatore ${ }^{1}$ \\ ${ }^{1}$ Department of Civil and Industrial Engineering, University of Pisa, Largo L. Lazzarino 1, 56122 Pisa, Italy \\ ${ }^{2}$ Institut für Stahlbetonbewehrung e.V., Kaiserswerther Strasse 137, 404-74 Düsseldorf, Germany \\ Correspondence should be addressed to Silvia Caprili; silvia.caprili@ing.unipi.it
}

Received 27 July 2015; Revised 26 October 2015; Accepted 28 October 2015

Academic Editor: Hiroshi Noguchi

Copyright (c) 2015 Silvia Caprili et al. This is an open access article distributed under the Creative Commons Attribution License, which permits unrestricted use, distribution, and reproduction in any medium, provided the original work is properly cited.

\begin{abstract}
The experimental results of a testing campaign including tensile and low-cycle fatigue tests on different reinforcing steel bar types in the as-delivered and corroded condition are presented. Experimental data were statistically analyzed adopting ANOVA technique; Performance Indicators (PIs), describing the mechanical performance characteristics of reinforcements, and Corrosion Damage Indicators (CDIs), describing the detrimental effects of corrosion phenomena, were determined and correlated in order to evaluate the influence of corrosion on the behaviour of reinforcing steels, providing useful information for designers in addition to what is presented in current standards.
\end{abstract}

\section{Introduction}

Reinforced concrete (r.c.) buildings in seismic areas are actually designed following the capacity design rules, adopted as reference technique by international design codes [1-3]. To satisfy the cyclic/seismic structural requirements, buildings shall guarantee enough ductile resources at global, element, and material level, that is, in terms of displacement, rotational capacity, and deformation, without significant losses of strength and stiffness. The global dissipative collapse mechanism of the building is achieved through the development of plastic deformations in correspondence with the ends of beams and columns: the rotational capacity of structural elements is strictly dependent on the ductility of steel reinforcing bars, generally expressed in terms of elongation to maximum load $\left(A_{\mathrm{gt}}\right)$ and hardening ratio $\left(R_{m} / R_{e}\right)$ with specific ranges imposed by European design standards for high or medium ductility class (HDC or MDC, resp.). For example, Eurocode 2 [4] defines three different ductility classes (A, B, and C) in relation to the values of $A_{\mathrm{gt}}$ and $R_{m} / R_{e}$, respectively, higher than $2.5 \%, 5.0 \%$, and $7.5 \%$ for $A_{\mathrm{gt}}$ and higher than 1.05 and 1.08 and between 1.15 and 1.35 for $R_{m} / R_{e}$. Eurocode 8 [1] provides additional specifications limiting the use of class $B$ to elements designed for MDC and the use of ductility class A is allowed by the Italian Standards for Constructions [2] only for stirrups.

The European design prescriptions are not directly reflected by the production scenario of reinforcing steel bars, characterized by the lack of a codified classification of steel grades (for what concerns both strength and ductility classes) and consequently resulting in a large variety of reinforcing steels produced in different countries, as widely discussed in Apostolopoulos et al. [5].

The limitations for the ductility properties of reinforcing steels actually provided by Eurocodes are mainly referred to the monotonic behaviour, while no information is given for the cyclic/seismic one. Current national production standards for reinforcing steel bars generally do not prescribe the execution of cyclic tests for the mechanical characterization and production control of the seismic behaviour of reinforcements. Only some European countries like Portugal, Spain, and Poland $[6,7]$ introduce specific protocols for the lowcycle fatigue tests on steel reinforcing bars with testing parameters different from one another. The lack of a deep knowledge about the cyclic behaviour of reinforcing bars is also highlighted by the wide variability of results presented in the current scientific literature [8-12]. 
As a consequence, despite the necessity of high ductile properties of reinforcements to be adopted in the dissipative regions of r.c. buildings, no specific prescriptions are given for guaranteeing the satisfaction of those seismic requirements. Trying to solve the presented problem, in the revision of European standard EN 10080:2005 [13, 14] (Steel for the reinforcement of concrete-weldable reinforcing steel) and in particular, Mandate M115 [15] proposes the definition of "the methods (calculation, test methods or others) or a reference to a standard containing the methods for the determination of such characteristics," introducing a cyclic loading performance for earthquake prone areas.

In addition to the need of the definition of the effective ductility of reinforcing steels, several studies presented in the current scientific literature evidenced a reduction of some performance characteristics after corrosion of TempCore steels, actually widely adopted for r.c. structures, able to easily satisfy the limitations imposed by European standards towards reasonable production costs. Apostolopoulos and Michalopoulos [16], Apostolopoulos and Papadakis [17], Al Hashemi et al. [18], and others [19-21] highlighted the strong decrease of the dissipative capacity of bars exposed to aggressive environmental condition, that is, subjected to corrosion phenomena, with the following degradation of the global bearing capacity of the whole structure. The deterioration of the ductility was evidenced in terms of both $A_{\mathrm{gt}}$ (i.e., monotonic behaviour) and dissipated energy under the execution of low-cycle fatigue tests (i.e., cyclic/seismic behaviour). Papadopoulos et al. [22], through the execution of salt spray chamber tests on two different steel grades with similar chemical composition, evaluated the quality index $Q_{d}$ for the quantification of the mechanical performance (yielding strength, elongation) with reference to different exposure periods.

In order to prevent corrosion phenomena of reinforcements, Eurocode 2 [4] prescribes, for new constructions, the adoption of adequate concrete strength and covers in relation to the different possible exposure conditions; anyway, the problem still remains in the case of existing buildings.

In the present work the effective mechanical performance (i.e., capacity) of steel reinforcing bars under low-cycle fatigue and monotonic actions in both uncorroded and corroded condition is deeply analyzed; the research work was developed as part of the European research project "Rusteel: Effects of Corrosion on Low-Cycle Fatigue (Seismic) Behaviour of High Strength Steel Reinforcing Bars" (2009-2012) [5, 21], aiming at evaluating the combined effects of corrosion phenomena and seismic action on the ductile properties of bars and of the ability of corroded samples still to withstand the requirements imposed by earthquakes.

A set of steel reinforcements representative for the actual European bars' production was selected and tested under monotonic and cyclic loads in both uncorroded (reference) and corroded conditions, opportunely reproduced through the execution of accelerated corrosion tests in salt spray chambers. The results of mechanical tests allowed the determination of significant parameters describing the dissipative behaviour of reinforcements, defined as "Performance Indicators" (PIs), representative of the structural performance of bars in the uncorroded (i.e., reference) condition. In particular, different PIs were defined in relation to the monotonic and cyclic behaviour of bars: the ductile capacity was evaluated in terms of mechanical properties and necking $\left(R_{e}, R_{m}\right.$, $A_{\mathrm{gt}}, R_{m} / R_{e}$, and $Z$ ) for monotonic tests and dissipated energy and number of cycles to failure $\left(\mathrm{dE}, N_{\text {cycles }}\right)$ in the case of lowcycle fatigue tests (LCF).

The severity of the corrosion attack was defined in relation to Corrosion Damage Indicators (CDIs) calibrated on the basis of laboratory experimental tests executed on reinforcements and suitably defined in relation to the effective exposure to which bars are subjected. Corrosion Damage Indicators (CDIs) were opportunely defined to correlate the deterioration of the mechanical properties and dissipative capacity (i.e., the performance indexes $R_{m}, R_{e}, A_{\mathrm{gt}} \mathrm{dE}$, and $N_{\text {cycles }}$ ) with the level and the intensity of the corrosion attack.

Specific relationships between CDIs which can be related to Classes of Exposure as defined in Eurocode 2 [4] and PIs were then provided analyzing the ability of steel reinforcing bars to maintain an adequate safety level in presence of seismic actions or less. What is herein presented allowed the determination of additional prescriptions for the protection of steel reinforcing bars from corrosion, with respect to the ones already presented in Eurocode 2 [4] about the thickness of the concrete cover.

\section{Determination of Corrosion Damage Indicators (CDIs) and Performance Indicators (PIs)}

2.1. Corrosion Damage Indicators (CDIs). In order to statistically analyze the influence of corrosion phenomena on the ductile behaviour of steel reinforcing bars, under both monotonic and cyclic loadings, significant parameters, Corrosion Damage Indicators (CDIs), describing the practical effects of aggressive environmental conditions on reinforcements were determined, on the base of what is presented in the current scientific literature and in standards. Relevant corrosion phenomena were initially classified in relation to the exposure classes presented in Eurocode 2 [4]; Table 1 presents, for example, the case of exposure class XS2 (i.e., corrosion due to chlorides from seawater). As visible, the corrosion rate (expressed in terms of mass loss, ML, i.e., corrosion and erosion rates) can be considered as a valid Corrosion Damage Indicator (CDI), for both uniform and local (pitting) corrosion, respectively, due to carbonation phenomena and to chlorides' ingress.

Looking at the current scientific literature, moreover, two additional parameters describing the effects of corrosion phenomena shall be taken into consideration: pit depth (in the case of localized corrosion) and the absorption of atomic hydrogen (in the following hydrogen) due to corrosion.

Gräfen [25] evaluated the influence of absorbed hydrogen on the mechanical performance for sensitive quenched and tempered prestressing steels, as represented in Figure 1(a); the obtained results, useful also for the analysis of TempCore reinforcements characterized by a quenched and tempered 
TABLE 1: Approach to classification according to table 4.1 of EN 1992-1-1:2005 [4].

\begin{tabular}{lll}
\hline $\begin{array}{l}\text { Class } \\
\text { designation }\end{array}$ & Description of the environment & $\begin{array}{l}\text { Informative examples where exposure classes may } \\
\text { occur }\end{array}$ \\
\hline
\end{tabular}

(2) Corrosion induced by carbonation

XC1 Dry or permanent dry Concrete inside buildings with low air humidity

Concrete permanently submerged in water

(4) Corrosion induced by chlorides from seawater

XS2 Permanently submerged Parts of marine structures

Practical corrosion rates and hydrogen activities

$\begin{array}{lll}\text { Class } & \text { Degree of corrosion Hydrogen activity } \\ \text { designation } & \text { Hydron }\end{array}$

(2) Corrosion induced by carbonation

$0-5$ relevant only for submerged in water conditions, Moersch [23]:

(i) $\mathrm{pH}$ value $\geq 12.6$

(ii) Extreme oxygen poverty; no oxygen

Average corrosion rates: $<0.5 \mu \mathrm{m} /$ year Max. erosion rates: $2 \mu \mathrm{m} /$ year, poor

$\mathrm{XC1}$ concrete strength, low cover and cracks [4] (iii) Maximum content of chlorides in raw materials not exceeded, no additional corrosive substances

1-10 for Moersch [23]:

(i) $\mathrm{pH}$ value $<12.6$

(ii) All oxygen contents

(iii) Maximum content of chlorides in raw materials not exceeded, no additional corrosive substances

(4) Corrosion induced by chlorides from sea water

1-15 for Moersch [23]:

(i) $\mathrm{pH}$ value $\geq 12.6$

(ii) Critical chloride content for corrosion exceeded:

Corrosion rates (mass loss)

XS2
1.16-11.6 $\mu \mathrm{m} /$ year (Rodriguez et al. [24])

$\sim 0.9-9 \mathrm{mg} /\left(\mathrm{cm}^{2}\right.$ year $)$ (a) very low oxygen content: $10-100 \mathrm{~mol} \mathrm{Cl} / \mathrm{mol} \mathrm{OH}^{-}$

(b) oxygen saturation: $0.1-1 \mathrm{~mol} \mathrm{Cl}^{-} / \mathrm{mol} \mathrm{OH}^{-}$

5-45 for Moersch [23]:

(i) $\mathrm{pH}$ value $<12.6$

(ii) Critical chloride content for corrosion exceeded:

(a) very low oxygen content:

$10-100 \mathrm{~mol} \mathrm{Cl}^{-} / \mathrm{mol} \mathrm{OH}^{-}$

(b) oxygen saturation: $0.1-1 \mathrm{~mol} \mathrm{Cl}^{-} / \mathrm{mol} \mathrm{OH}^{-}$ martensitic microstructure in the outer layer of the steel, evidenced the drop of ductility (in terms of ultimate elongation, A) depending on hydrogen contents for different nominal tensile strength levels.

The relevance of hydrogen content for the performance of reinforcing steels under low-cycle fatigue loads was also evidenced in the results presented by Riecke [26]. Figure 1(b) shows the influence of the strain rate after hydrogen absorption (high hydrogen activities) on the elongation for a quenched and tempered prestressing steel: with increasing strain rate the elongation values in solution (i.e., hydrogen absorption conditions) converged to the values of the elongation of the CERT-test in air. The strain rates used for lowcycle fatigue tests ranged from $10^{-3}$ to $10^{-2} \mathrm{~s}^{-1}$, and a loss of elongation of about $20 \%$ was observed for such strain rates. Looking at Figure 1, it can be concluded that hydrogen content does not play an important role in static conditions but may be relevant to low-cycle fatigue performance.
According to Neubert and Nürnberger [27], a pit depth of about $0.5 \mathrm{~mm}$ was correlated to a loss of elongation at fracture $(A)$ of about $30 \%$ for a very sensitive high strength quenched and tempered prestressing steel. Rehm et al. [28] deeply analyzed the correlation between corrosion erosion of the surface of embedded rebars in cracked concrete due to chloride induced corrosion and the pit depth. The results are presented in Figure 2. It can be concluded that pit depths with significant consequences on the residual mechanical performance of reinforcing steels could be obtained already for rather small rust layers.

As a consequence, for the analysis of the relation between CDI and the residual performance of reinforcing steel after corrosion, mass loss was considered the most appropriate damage indicator, easily measured and related to exposure classes and exposure durations through the adoption of specific calculations. Furthermore the influences of pit depth and absorbed hydrogen were also taken into consideration in the analysis of the results of the salt spray tests. 


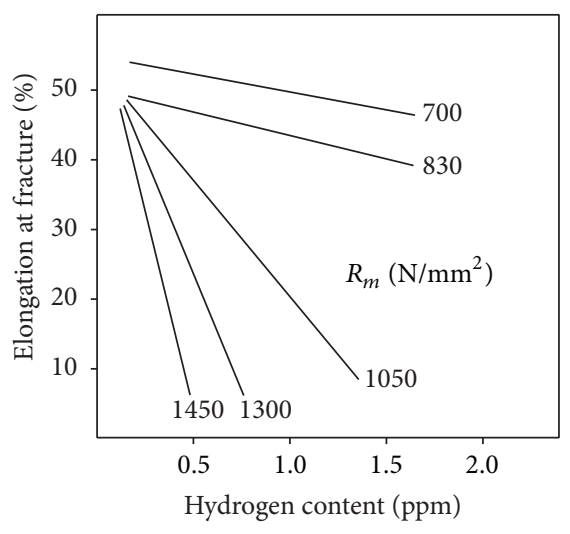

(a)

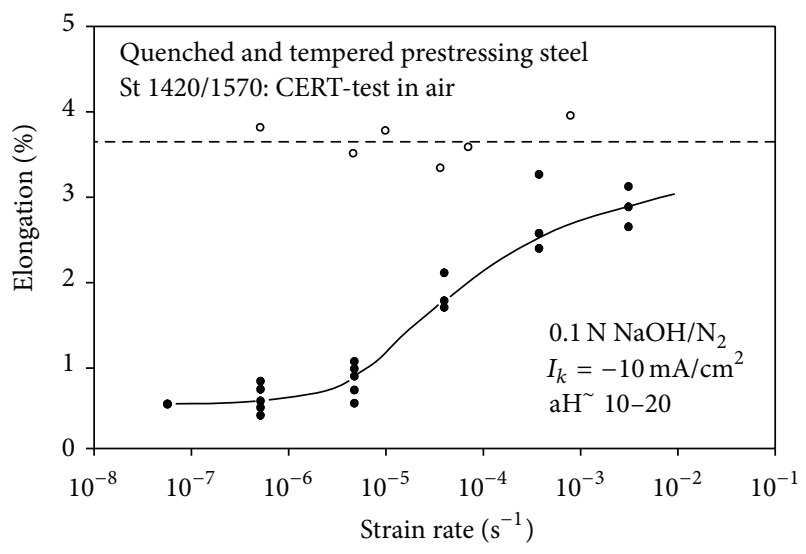

(b)

Figure 1: (a) Influence of $\mathrm{H}$ content on different steel types [24]; (b) influence of strain rate after $\mathrm{H}_{2}$-absorption on elongation [26].

\begin{tabular}{|c|c|c|c|}
\hline $\begin{array}{c}\mathrm{RD} \\
(\mathrm{mm})\end{array}$ & $\begin{array}{l}\text { KF } \\
(\%)\end{array}$ & $\begin{array}{c}\mathrm{KA} \\
(\mathrm{mm})\end{array}$ & $\begin{array}{c}\mathrm{NT} \\
(\mathrm{mm})\end{array}$ \\
\hline $2-3$ & \multirow{5}{*}{$>25$} & \multicolumn{2}{|c|}{$\leq 3.0$} \\
\hline $1-1.5$ & & $\leq 0.5$ & $\leq 2.0$ \\
\hline $0.2-0.5$ & & $\leq 0.2$ & $\leq 1.5$ \\
\hline$<0.1$ & & $\ll 0.1$ & $\leq 1.0$ \\
\hline$<0.1$ & & $\ll 0.1$ & $\leq 0.15$ \\
\hline$<0.1$ & $\leq 25$ & $\ll 0.1$ & $\leq 0.15$ \\
\hline
\end{tabular}

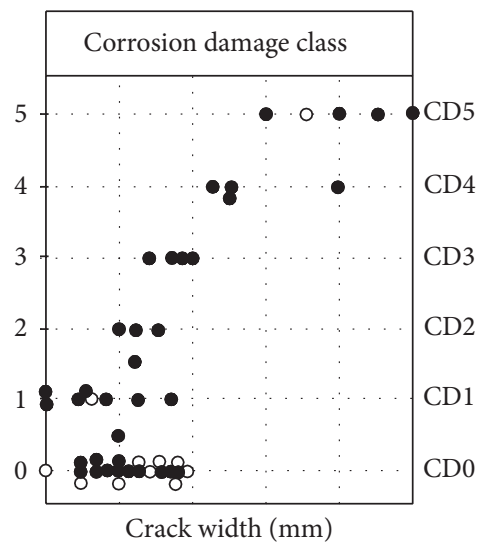

Exposition class: XS3 - splash water, seafront, 30-year-old port mole Concrete cover: $30-50 \mathrm{~mm}$; concrete strength approx. $50 \mathrm{MPa}$ Reinforcement $\phi 12-20 \mathrm{~mm}$

RD: thickness of rust layer; KF: corroded surface

KA: corrosion erosion; NT: pit depth

FIGURE 2: Degree of corrosion depending on crack width for XS3 and an exposure duration of 30 years [28].

2.2. Performance Indicators (PIs). The effects of corrosion, with reference to the CDIs previously determined, were evaluated in relation to significant Performance Indicators (PIs) able to describe the mechanical behaviour of steel reinforcing bars after the exposure to aggressive environmental conditions. In particular, PIs were determined for both the monotonic and the low-cycle fatigue (i.e., representing earthquakes) behaviour.

According to what is presented in the current scientific literature $[5,17,29]$ all the mechanical performance characteristics of bars (yield strength $R_{e}$, tensile strength $R_{m}$, hardening ratio $\left(R_{m} / R_{e}\right)$, strain at maximum load $A_{\text {gt }}$, and necking strain $Z$ ) were taken into consideration for the monotonic behaviour.

For what concerns, on the other hand, the cyclic/seismic behaviour of reinforcements, despite the possible variation of imposed deformation, testing frequency, length of the specimens, and other parameters strictly related to the adopted experimental testing protocol, the two considered PIs were, once again in relation to data actually presented in the scientific literature, the total dissipated energy density $(\mathrm{dE})$ and the number of cycles to failure $(N)$. The total dissipated energy was evaluated according to the formulation proposed by Apostolopoulos [29] as an approximation of the engineering stress-strain curve: $\mathrm{dE}=\int \sigma d \varepsilon$.

The selection of PIs can be directly related to the results obtained from numerical analyses deeply reported in Braconi et al. [30], also developed in the framework of Rusteel research project [5]; according to [30, 31], Incremental Dynamic Analyses (IDAs) executed on representative r.c. buildings designed following [1] evidenced two possible behaviours of reinforcing steels: the first one is typical of those elements, mainly beams (Figure 3(a)) characterized by high deformations in tension due to seismic action (around 6.0\%) and low dissipated energy density (around $40 \mathrm{MPa}$ ) due to the inability to execute complete reversed tension/compression cycles. In this case, the main parameter affecting the description of the mechanical behaviour of the rebar is $A_{\mathrm{gt}}$, since the seismic action leads to a behaviour similar to the monotonic tensile one (PI for monotonic behaviour). The second condition is, on the other hand, typical of those elements (mainly columns, Figure 3(b)) in which the seismic input is able to produce few (one, maximum two) complete reversed tension/compression cycles with high levels of deformation (around 6.0 and $-4.0 \%$ ) and high density of dissipated energy (around $120 \mathrm{MPa}$ ). In this case, the parameter describing the seismic behaviour of rebar (PI for cyclic behaviour) is the dissipated energy density $\mathrm{dE}$.

\section{Mechanical Characterization of Reinforcements in Uncorroded and Corroded Conditions}

3.1. Determination of the Sample. A representative set of reinforcing bars was selected for experimental tests. Different steel grades (nominal $R_{e}$ equal to 400,450 , and $500 \mathrm{MPa}$ ), 


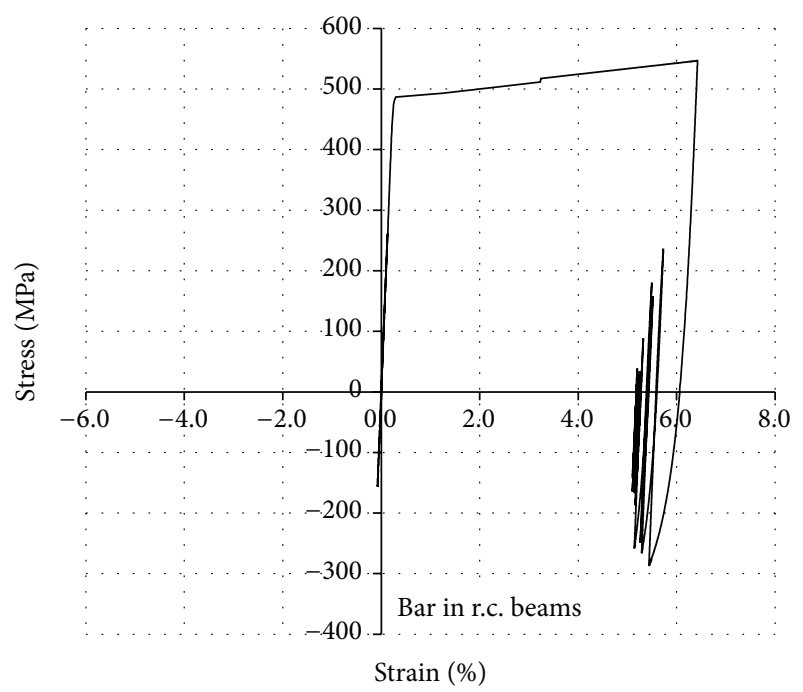

(a)

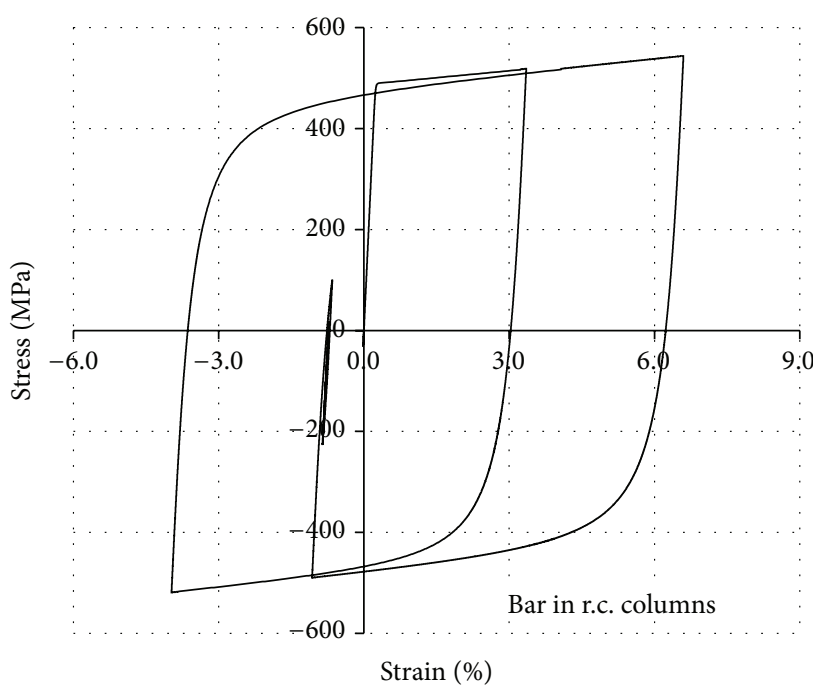

(b)

FiguRE 3: (a) Numerical stress-strain diagrams for bars in r.c. beams, (b) numerical stress-strain diagrams for bars in r.c. columns.

ductility classes (A, B, and C), diameters (between 8 and $25 \mathrm{~mm}$ ), and production processes (TempCore, TEMP, microalloyed, MA, stretched, STR, Cold Worked, CW) were adopted, covering in a reasonable way the large variability of properties evidenced at European level. Steel reinforcing bars were provided by two European producers involved as partners of the research project (hereafter indicated as "producer 1" and "producer 2"); tests were executed by three different European laboratories (one in Greece, one in Italy, and the last one in Portugal, in the following determined, respectively, as "Lab. A," "Lab. B," and "Lab. C"). The complete set of steel bars selected for the execution of mechanical experimental tests in corroded and uncorroded condition is hereafter summarized:

(i) B400C, $\phi 16 \mathrm{~mm}, \mathrm{MA}$, producer 2, Lab. B and C.

(ii) B400C, $\phi 16 \mathrm{~mm}$, TEMP, producer 1, Lab. A, B and C.

(iii) B400C, $\phi 25 \mathrm{~mm}, \mathrm{MA}$, producer 2, Lab. B and C.

(iv) B450C, $\phi 12 \mathrm{~mm}$, STR, producer 1, Lab. C.

(v) B450C, $\phi 16 \mathrm{~mm}$, TEMP, producer 1, Lab. A, B and C.

(vi) B450C, $\phi 25 \mathrm{~mm}$, TEMP, producer 2, Lab. B and C.

(vii) B500A, $\phi 12 \mathrm{~mm}, \mathrm{CW}$, producer 2, Lab. B and C.

(viii) B500B, $\phi 12 \mathrm{~mm}$, STR, producer 1, Lab. C.

(ix) B500B, $\phi 16 \mathrm{~mm}$, TEMP, producer 1, Lab. A, B and C.

(x) B500B, $\phi 25 \mathrm{~mm}$, TEMP, producer 2, Lab. B and C.

\subsection{Mechanical Characterization of Uncorroded Steel Bars.} Tensile and low-cycle fatigue tests were executed on selected reinforcing steel bars. Tensile tests were executed according to EN 15630-1:2010 [32]; for each steel grade, diameter, process, and producer three tensile tests were executed on specimens of adequate length (about $600 \mathrm{~mm}$ ). In the following analyses, the mean values of the mechanical properties obtained for each significant parameter (i.e., yielding and tensile strength, elongation at maximum load, and ultimate elongation) were adopted. The detailed results of tensile tests are widely presented in Apostolopoulos et al. [5] ${ }^{1}$.

For the execution of cyclic (LCF) tests, a specific testing protocol was elaborated as part of the Rusteel project. The definition of a codified methodology for the execution of cyclic tests was necessary since in the current scientific literature and in actual European standards different protocols are presented, with variable testing frequencies $(f)$, imposed deformation $(\Delta \varepsilon)$, free length of the specimen $\left(L_{0}\right)$, and number of cycles $(N)$. The reasons at the base of the elaboration of the low-cycle fatigue protocol were widely presented by [33], taking into account, beside the actual prescriptions of current standards and literature, the effective seismic demand on reinforcing bars, as presented in [30].

Two levels of imposed deformation, respectively, equal to $\pm 2.5 \%$ and $\pm 4.0 \%$, were adopted for the execution of at least 20 symmetrical hysteretic cycles or until fracture. The imposed strain and the number of cycles were defined in relation to the results of numerical analyses presented in Braconi et al. [30] on r.c. case study buildings opportunely designed according to Eurocodes 2 and $8[1,4]$ and subjected to incremental dynamic analyses with specific natural accelerograms selected to maximize the seismic demand on steel reinforcing bars, obtaining the maximum level of deformation and the total dissipated energy due to earthquake events.

The free length of the sample was assumed equal to 6 or 8 diameters, in order to represent the condition of bars in r.c. elements in HDC or MDC according to [1]. For the testing frequency, since different values are adopted in experimental tests (varying between 0.005 and $3.0 \mathrm{~Hz}$ ), preliminary tests were executed [5] for the evaluation of the influence of the testing frequency on the results of cyclic tests in terms of dissipated energy. The results of preliminary tests, executed on bars $\phi 16 \mathrm{~mm}$ with frequency equal to $0.05 \mathrm{~Hz}$ and $2.0 \mathrm{~Hz}$, 
TABLE 2: Experimental results of LCF tests for different testing frequency and percentage differences.

\begin{tabular}{|c|c|c|c|c|c|c|c|}
\hline Frequency & $2.0 \mathrm{~Hz}$ & $0.05 \mathrm{~Hz}$ & $L_{0}=6 \phi$ & Frequency & $2.0 \mathrm{~Hz}$ & $0.05 \mathrm{~Hz}$ & $L_{0}=8 \phi$ \\
\hline Cycle & $\Delta E[\mathrm{MPa}]$ & $\Delta E[\mathrm{MPa}]$ & Difference [\%] & Cycle & $\Delta E$ & $\Delta E$ & Difference [\%] \\
\hline 1 & 31.7 & 33 & $3.90 \%$ & 1 & 31.6 & 33.7 & $6.4 \%$ \\
\hline 2 & 31.5 & 33 & $4.50 \%$ & 2 & 31.7 & 29.8 & $6.2 \%$ \\
\hline 3 & 30.9 & 32.4 & $4.60 \%$ & 3 & 28.3 & 27.8 & $1.8 \%$ \\
\hline 4 & 29.4 & 31.8 & $7.50 \%$ & 4 & 25.7 & 25.2 & $1.9 \%$ \\
\hline 5 & 29.3 & 31.1 & $5.80 \%$ & 5 & 23.7 & 23.3 & $1.8 \%$ \\
\hline 6 & 28.4 & 30.5 & $6.90 \%$ & 6 & 22.1 & 21.7 & $1.8 \%$ \\
\hline 7 & 27.8 & 29.9 & $7.00 \%$ & 7 & 20.8 & 20.4 & $2.0 \%$ \\
\hline 8 & 27.3 & 29.4 & $7.10 \%$ & 8 & 19.6 & 19.2 & $2.5 \%$ \\
\hline 9 & 26.2 & 28.8 & $9.00 \%$ & 9 & 18.5 & 18.0 & $3.1 \%$ \\
\hline 10 & 26.0 & 28.6 & $9.10 \%$ & 10 & 17.5 & 17.0 & $3.1 \%$ \\
\hline 11 & 25.8 & 27.7 & $6.90 \%$ & 11 & 16.3 & 16.0 & $2.1 \%$ \\
\hline 12 & 25.2 & 27.1 & $7.00 \%$ & 12 & 15.0 & 15.1 & $1.0 \%$ \\
\hline 13 & 24.6 & 26.3 & $6.50 \%$ & 13 & 13.3 & 14.3 & $6.8 \%$ \\
\hline 14 & 23.8 & 25.5 & $6.70 \%$ & & & & \\
\hline 15 & 23.2 & 24.2 & $4.10 \%$ & & & & \\
\hline 16 & 22.6 & 21.6 & $4.60 \%$ & & & & \\
\hline Total & 433.7 & 460.9 & $5.90 \%$ (tot) & & 284.1 & 281.5 & $0.92 \%$ (tot) \\
\hline
\end{tabular}

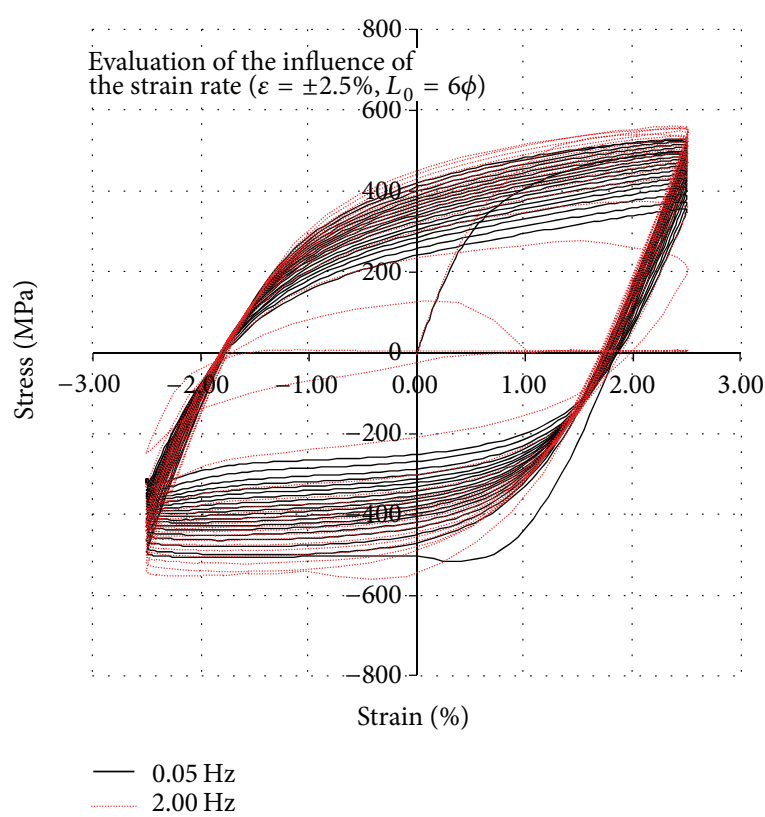

(a)

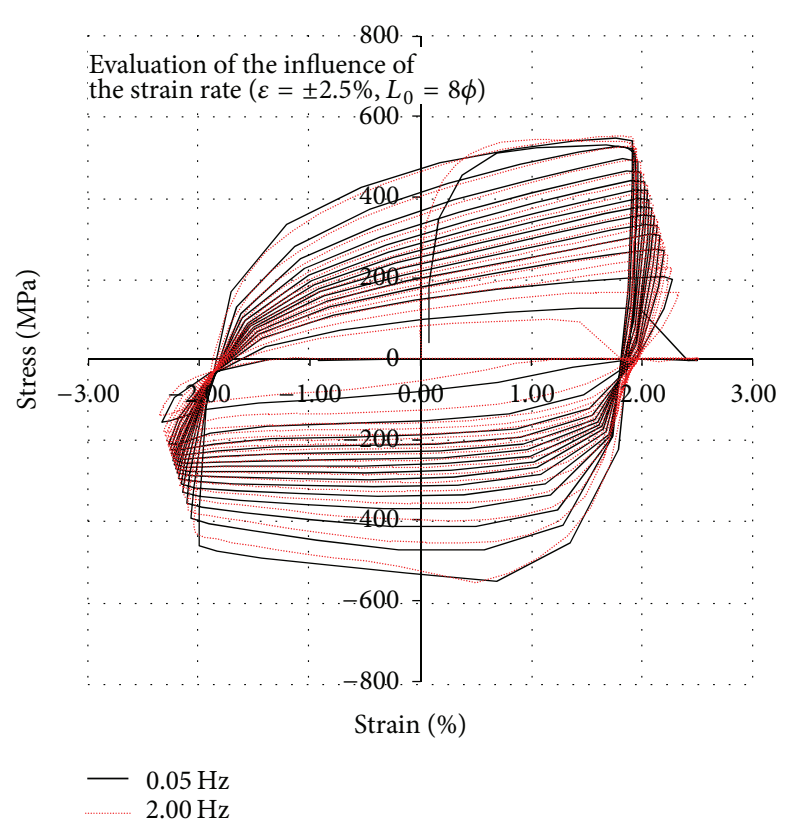

(b)

FIGURE 4: Stress-strain curve from LCF tests on specimens B450C-TEMP (prod. 2) $16 \mathrm{~mm}$ with frequency equal to 0.05 and $2.0 \mathrm{~Hz}$.

evidenced differences in terms of dissipated energy (total and per cycle) lower than 5-10\%; similar values, highlighting the relatively low influence of the strain rate on the global dissipative behaviour of the specimens, were found by Crespi [10]. Table 2 presents the results obtained from preliminary tests, while in Figure 4 the stress-strain diagrams are shown.

As a consequence, the testing frequency was fixed to $2.0 \mathrm{~Hz}$, with possible reduction up to $0.05 \mathrm{~Hz}$ in relation to the machine's requirements for samples of diameter higher than
$16.0 \mathrm{~mm}$. The preliminary protocol can be then summarized as follows:

(i) frequency $f=2.0 \mathrm{~Hz}(0.05 \mathrm{~Hz}$ for $\phi \geq 16 \mathrm{~mm})$;

(ii) two levels of imposed deformation: $\varepsilon_{1}= \pm 2.5 \%$ and $\varepsilon_{2}= \pm 4.0 \%$;

(iii) minimum number of cycles equal to 20; 
(iv) two different values of the free length: $L_{0, \mathrm{HDC}}=6 \phi$ (HDC) and $L_{0, \mathrm{MDC}}=8 \phi(\mathrm{MDC})$.

Two tests for each steel grade, diameter, process, producer, level of imposed strain, and free length of the specimens were executed. The complete list of results can be found in Apostolopoulos et al. [5] $]^{1}$.

\subsection{Mechanical Characterization of Corroded Steel Bars.} Reinforcing bars were subjected to accelerated corrosion tests in salt spray chamber to evaluate the effects of aggressive environmental conditions on their monotonic and cyclic/seismic behaviour.

The protocol adopted for the accelerated corrosion tests was elaborated as part of Rusteel research project [5], on the base of an accurate survey and technical evaluation of the actual procedures used for such kind of experimental tests. The salt spray chamber test was selected in relation to practical and efficiency requirements, such as easiness in the preparation of the samples, limited duration of the exposure period, possibility to evaluate and control the relevant parameters, and availability of codified procedures.

A protocol based on ASTM B117-11 [34] was modified in relation to the specific requirements of the research project. Two different exposure periods (i.e., 45 and 90 days) were considered; the protocol was organized into 3 different phases (i.e., preparation of testing apparatus, positioning and execution of corrosion tests, and analysis of corrosion damage), following ISO 9227 [35] for the preparation of the specimens.

The first phase consisted in the preparation of the testing apparatus and cleaning the chamber, piping, and solution tanks from the residuals of previous experiments in order to obtain a $\mathrm{pH}$ of the chamber between 5.5 and 6.2. To stabilize the $\mathrm{pH}$ of the chamber before the positioning of the samples, 50 litres of solution was introduced in the chamber for about 6 hours under the predetermined wet/dry cycles.

For the second phase the length of the specimens was fixed between 500 and $600 \mathrm{~mm}$ to allow the execution of tensile tests. In the middle section of the testing article a high temperature nonadhesive tape (of length equal to $20 \mathrm{~mm}$ or, at least, the distance between two consecutive ribs) was placed to determine the unprotected part of the specimen; paraffin was used to avoid corrosion in the other part of the bar. The testing samples were then placed inside the chamber at an angle of $45-60^{\circ}$ to the supports and rotated by $90^{\circ}$ at least three times a day, in order to prevent the generation of salts according to what is prescribed by ISO 9227 [35] for the whole duration of the test. 8 wet/dry cycles every 24 hours $(90$ minutes dry followed by 90 minutes wet), with a continuous control of the $\mathrm{pH}$ of the chamber and of the procedure, were then executed. At the end of the test, the specimens were rubbed and cleaned and maintained at a temperature of about $-5^{\circ}$ to avoid the loss of the volatile part of hydrogen before the execution of mechanical tests.

Cross-sectional analyses, SEM evaluations, measures of notch depth, crack depth and width, hydrogen content, cross section reduction, and, in particular, mass loss were executed.

After the exposure in salt spray chamber, corroded specimens were subjected to monotonic and cyclic tests, following, respectively, the prescriptions of EN ISO 15630-1 [32] and the protocol already showed for tests on reference bars [5]. At least three tensile tests on each steel grade/diameter/process and two cyclic tests for each level of imposed deformation and free length of the specimens were executed.

The results of mechanical tests on corroded specimens were evaluated in terms of decrease of the significant mechanical properties towards parameters significantly highlighting the effects of deterioration due to corrosion in salt spray chamber. The complete set of results of monotonic tensile and low-cycle fatigue tests on corroded specimens is presented in Rusteel research project [5] ${ }^{1}$, since it is not possible for reasons of brevity to directly insert all the data in the present paper.

Tables 4 and 5 show, for example, some of the values of residual mechanical properties for reinforcing steel bars after, respectively, monotonic tensile and low-cycle fatigue tests. In the case of monotonic tests, the residual strength and elongation are presented for the mean values of mass loss, while for low-cycle fatigue tests the residual total dissipated energy and the specified number of cycles (i.e., ratio between cycles to failure after and before corrosion) are provided. As visible from Table 3, significant differences were revealed in the mass loss obtained from different laboratories; although the protocol adopted for the execution of accelerated corrosion tests was exactly the same, the difference shall be justified only in relation to the effective environmental conditions reproduced inside different chambers.

Figure 5(a) shows the comparison between the stressstrain diagrams obtained from corroded (curves of specimens $n^{\circ} 1,2,3,4$, and 6) and uncorroded specimens (B450C, diameter $16 \mathrm{~mm}$, curves Ref.1, Ref.2, and Ref.3) under tensile tests while Figure 5(b) presents the values of the mean total dissipated energy of corroded and uncorroded specimens (B450C and B500B, diameter $16 \mathrm{~mm}$ ).

\section{Evaluation of the Effects of Accelerated Corrosion on Corrosion Damage Indicators}

4.1. CDI Mass Loss. In a first step a statistical analysis adopting ANOVA technique (ANalysis Of VAriance) was carried out on the mass loss (ML) results obtained in the salt spray chambers with different reinforcing steels, in order to evaluate the influence of independent parameters such as type of production, nominal yielding strength $\left(R_{e, \text { nom }}\right)$, nominal diameter $\left(d_{\text {nom }}\right)$, ductility class, time of corrosion test $\left(T_{\text {corr }}\right)$, and salt spray chamber or Lab., respectively, on the dependent factor mass loss. Figures 6 and 7 present the results of the multiparameter ANOVA tests. It can be concluded that the most significant influence on mass loss was the laboratory in which the salt spray tests were carried out: a well-defined procedure was followed in all three laboratories; nevertheless the corrosion conditions within each salt spray chamber were not completely reproducible. There is a tendency that exposure period in salt spray chamber $\left(T_{\text {corr }}\right)$ also influenced the obtained results; an increase of the corrosion time could be associated with the increase of the mass loss: mean values 
TABLE 3: Mean values and coefficient of variation of residual mechanical properties of corroded bars (16 and $25 \mathrm{~mm}$ ), tensile tests.

\begin{tabular}{lcccccccccccc}
\hline Steel grade/process & $\begin{array}{c}d_{\text {nom }} \\
{[\mathrm{mm}]}\end{array}$ & $\mathrm{Lab}$ & $\begin{array}{c}T_{\text {corr }} \\
{[\text { days }]}\end{array}$ & $\begin{array}{c}\mathrm{ML} \\
{[\%]}\end{array}$ & $\begin{array}{c}\text { res. } R_{e} \\
{[\%]}\end{array}$ & $\begin{array}{c}\mathrm{Cv}_{\text {res. } R_{e}} \\
{[\%]}\end{array}$ & $\begin{array}{c}\text { res. } R_{m} \\
{[\%]}\end{array}$ & $\begin{array}{c}\mathrm{Cv}_{\text {res. } R_{m}} \\
{[\%]}\end{array}$ & $\begin{array}{c}\text { res. } R_{m} / R_{e} \\
{[\%]}\end{array}$ & $\begin{array}{c}\mathrm{Cv}_{\text {res. } R_{e} / R_{m}} \\
{[\%]}\end{array}$ & $\begin{array}{c}\text { res. } A_{\text {gt }} \\
{[\%]}\end{array}$ & $\begin{array}{c}\mathrm{Cv}_{\text {res. } A_{\text {gt }}} \\
{[\%]}\end{array}$ \\
\hline B400C-TEMP & 16 & $\mathrm{~A}$ & 90 & 9.3 & 93.6 & 1.7 & 89.7 & 1.0 & 95.8 & 2.3 & 29.9 & 11.8 \\
B450C-TEMP & 16 & $\mathrm{~A}$ & 90 & 10.9 & 94.9 & 2.4 & 90.4 & 2.6 & 95.2 & 3.3 & 27.1 & 20.9 \\
B500B-TEMP & 16 & $\mathrm{~A}$ & 90 & 10.8 & 93.7 & 0.4 & 89.0 & 0.9 & 93.8 & 1.9 & 21.1 & 11.6 \\
B400C-TEMP & 16 & B & 90 & 16.4 & 92.9 & 1.8 & 94.5 & 0.9 & 101.7 & 2.5 & 44.8 & 11.6 \\
B450C-TEMP & 16 & B & 90 & 10.3 & 96.5 & 2.0 & 99.2 & 1.1 & 102.8 & 1.0 & 39.0 & 14.0 \\
B500B-TEMP & 16 & B & 90 & 24.7 & 87.6 & 1.3 & 93.7 & 0.8 & 106.8 & 1.2 & 47.6 & 7.6 \\
B450C-TEMP & 16 & C & 90 & 3.2 & 96.3 & 1.4 & 97.7 & 1.3 & 101.4 & 1.2 & 45.6 & 26.4 \\
B500B-TEMP & 16 & C & 90 & 0.3 & 95.2 & 1.1 & 95.1 & 0.9 & 99.9 & 0.6 & 70.7 & 24.2 \\
B400C-TEMP & 16 & C & 90 & 0.3 & 97.4 & 2.3 & 96.8 & 0.7 & 99.4 & 1.9 & 75.5 & 9.9 \\
B450C-TEMP & 25 & B & 90 & 3.8 & 97.4 & 1.5 & 97.5 & 0.6 & 100.1 & 0.9 & 62.6 & 8.3 \\
B500B-TEMP & 25 & B & 90 & 9.0 & 99.0 & 0.4 & 97.1 & 0.5 & 98.2 & 0.3 & 72.7 & 4.4 \\
B450C-TEMP & 25 & C & 90 & 1.4 & 100.9 & 0.9 & 99.0 & 0.7 & 98.1 & 1.2 & 83.7 & 9.3 \\
B500B-TEMP & 25 & C & 90 & 1.7 & 99.5 & 0.9 & 97.2 & 0.9 & 97.5 & 1.3 & 72.4 & 19.4 \\
\hline
\end{tabular}

TABLE 4: Average values and coefficient of variation of residual mechanical properties of corroded bars, cyclic tests.

\begin{tabular}{|c|c|c|c|c|c|c|c|c|c|c|c|}
\hline Steel grade/process & $\begin{array}{c}d_{\mathrm{nom}} \\
{[\mathrm{mm}]}\end{array}$ & Lab. & $\begin{array}{c}T_{\text {corr }} \\
\text { [days] }\end{array}$ & $\begin{array}{c}\Delta \varepsilon \\
{[\%]}\end{array}$ & $L_{0}$ & $\begin{array}{l}\text { ML } \\
{[\%]}\end{array}$ & $\begin{array}{c}\mathrm{Cv}_{\mathrm{ML}} \\
{[\%]}\end{array}$ & $\begin{array}{c}\text { res.dE } \\
{[\%]}\end{array}$ & $\begin{array}{c}\mathrm{Cv}_{\text {res.dE }} \\
{[\%]}\end{array}$ & $\begin{array}{c}N_{\text {corr }} / N_{0} \\
{[-]}\end{array}$ & $\begin{array}{c}\mathrm{Cv}_{N_{\text {corr }} / N_{0}} \\
{[\%]}\end{array}$ \\
\hline B400C-MA & 16 & A & 90 & \pm 2.5 & $6 \phi$ & 9.50 & $5.7 \%$ & 64.68 & $5.0 \%$ & 0.58 & $5.6 \%$ \\
\hline B400C-MA & 16 & B & 90 & \pm 2.5 & $6 \phi$ & 8.18 & $19.2 \%$ & 85.67 & $19.9 \%$ & 0.73 & $14.2 \%$ \\
\hline B400C-TEMP & 16 & A & 90 & \pm 2.5 & $6 \phi$ & 9.19 & $7.4 \%$ & 80.15 & $29.3 \%$ & 0.74 & $36.4 \%$ \\
\hline B450C-TEMP & 16 & A & 90 & \pm 2.5 & $6 \phi$ & 9.20 & $3.6 \%$ & 58.77 & $15.6 \%$ & 0.47 & $16.1 \%$ \\
\hline B450C-TEMP & 16 & $\mathrm{~B}$ & 90 & \pm 2.5 & $6 \phi$ & 6.25 & $44.6 \%$ & 88.31 & $28.6 \%$ & 0.86 & $15.4 \%$ \\
\hline B500B-TEMP & 16 & $\mathrm{~B}$ & 90 & \pm 2.5 & $6 \phi$ & 7.25 & $8.8 \%$ & 93.75 & $7.3 \%$ & 0.95 & $6.4 \%$ \\
\hline
\end{tabular}

TABLE 5: Hydrogen activities in salt spray tests.

\begin{tabular}{lcc}
\hline Material & $\begin{array}{c}\text { Measured range of } \mathrm{H}_{2} \\
\text { concentration in salt } \\
\text { spray tests }[\mathrm{ppm}]\end{array}$ & $\begin{array}{c}\text { Derived } \mathrm{H}_{2} \text {-activity } \\
{[-], \mathrm{C}_{0}=10^{-8}} \\
{\left[\mathrm{~mol} \mathrm{H} / \mathrm{cm}^{3} \mathrm{Fe}\right]}\end{array}$ \\
\hline $\begin{array}{l}\text { TempCore, } \\
\text { martensitic } \\
\text { microstructure }\end{array}$ & $0.5-1.1$ & 156 to 859 \\
\hline $\begin{array}{l}\text { Microalloyed, } \\
\text { pearlitic } \\
\text { microstructure }\end{array}$ & 0.2 & 156 \\
\hline
\end{tabular}

for 45 and 90 days of exposure were, respectively, around $0.5-$ $10 \%$ and between 1.5 and $12 \%$. Nominal diameter, production type, ductility class, and nominal yield strength did not evidence a strong influence on the obtained values of mass loss.

Taking into account the results of the ANOVA analysis the distribution tests were carried out for each laboratory separately. It was found that the distribution of the ML was best approximated with a gamma function (Figure 8) or, in alternative for an indicative analysis, with a Gauss distribution. Mass loss results showed a large scatter, with variation coefficients generally higher than $30 \%$. These variation coefficients for corrosion tests in salt spray testing are not unusual. With respect to the determination of the residual mechanical performance of the corroded rebars it was therefore necessary to measure for each tensile test the mass loss of the tested bar.

4.2. CDI Pit Depth. In order to understand the relation between pit depth in accelerated salt spray test and pit depth in salt containing mortar (i.e., embedded samples in practical conditions), measurements of pit depth were carried out on the corroded reinforcement samples. Experimental tests on embedded bars were performed in 90 r.c. specimens, with steel bar B500B of diameters 8,10 , and $12 \mathrm{~mm}$, for an exposure period equal to 180 days in salt spray chamber. Concrete class $\mathrm{C} 16 / 20$ and concrete cover equal to $10 \mathrm{~mm}$ were selected, able to quickly gain the effects of corrosion on steel and representing the condition of the majority of existing r.c. buildings.

Executed investigations evidenced that, as already observed for mass loss, the distribution of pit depth on an embedded bar could be approximated with a gamma function (Figure 9); for what concerns the salt spray chamber tests, on the other hand, no sufficient data were available to analyze the distribution function. In any case, a simple comparison of 


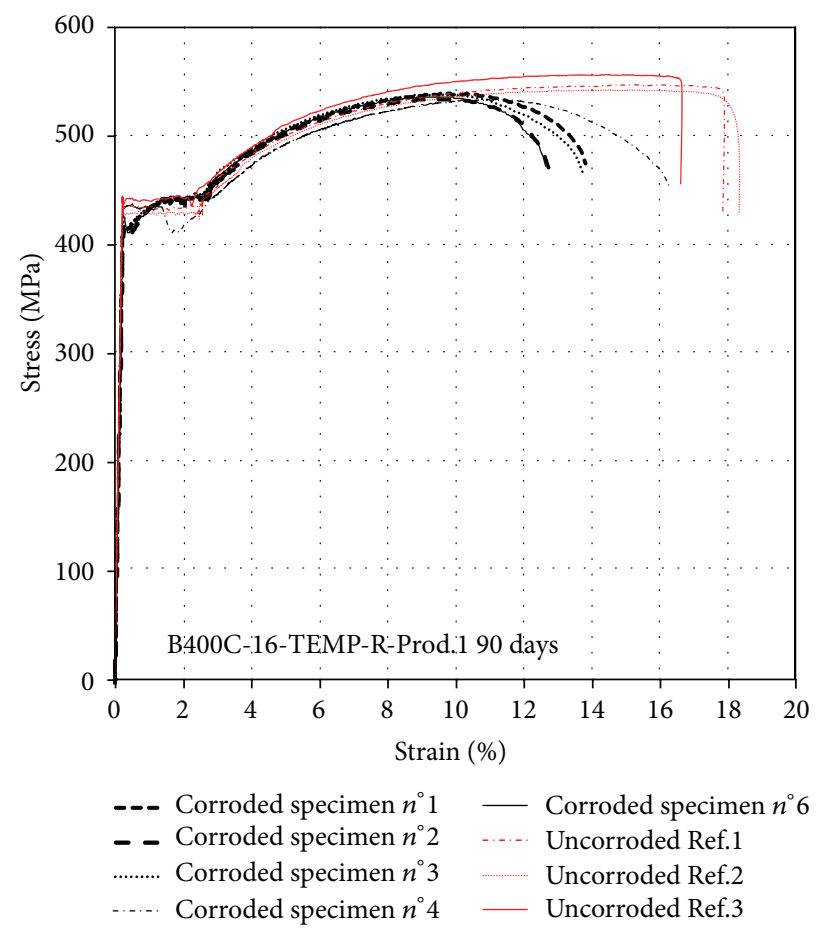

(a)

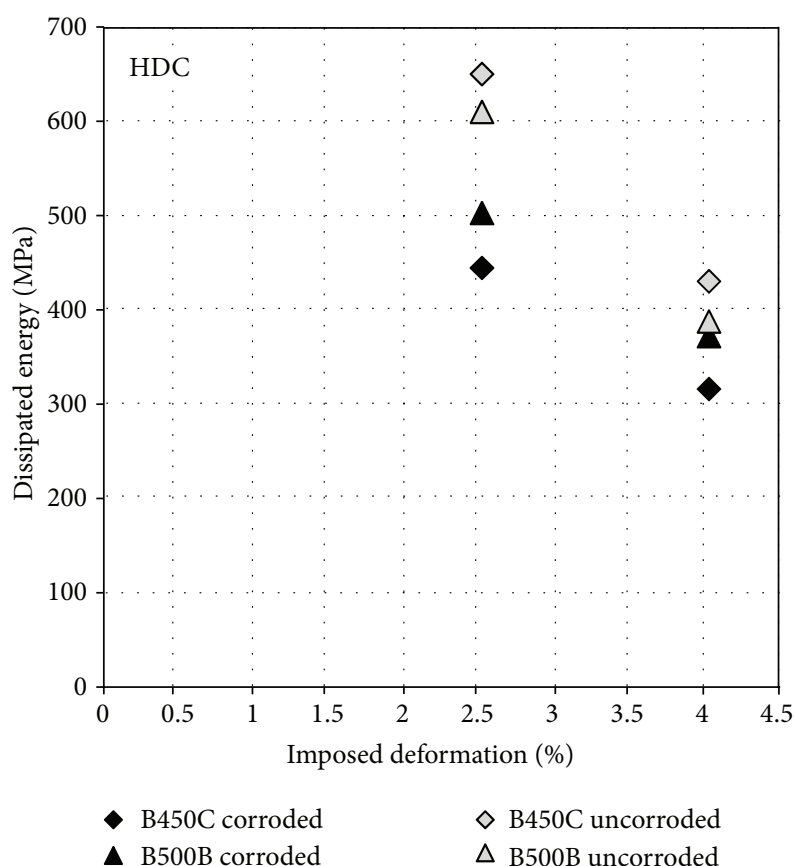

(b)

FiguRE 5: (a) Comparison of stress-strain curves obtained from uncorroded (curves Uncorroded Ref.1, Ref.2, and Ref.3) and corroded (curves of specimens $n^{\circ} 1,2,3,4$, and 6) specimens (B400C-16-TEMP, 90 days of corrosion, Lab. B), (b) comparison of the mean dissipated energy obtained from corroded and uncorroded specimens (B450C and B500B) for two different levels of imposed deformation and $L_{0}=6 \phi$.

the obtained pit depth values for both corrosion conditions (i.e., embedded and salt spray) is presented in Figure 10. The difference revealed in pit depths for similar values of mass loss is significant: the maximum value of pit depth obtained for samples coming from salt spray tests is on the level of the lowest value measured for the embedded samples. Similar results were obtained in [36] for embedded samples and bare samples exposed to salt spray testing. For similar mass losses of approximately $2.4 \%$ the pit depth was higher for the embedded samples, with an average value of $0.477 \mathrm{~mm}$ with respect to the bare samples with $0.390 \mathrm{~mm}$.

In [37] the pit depth values were compared for embedded samples in cracked and uncracked concrete containing 3.0\% $\mathrm{CaCl}$. The concrete samples were submitted to wet/dry cycles for six years. For the uncracked concrete a mass loss equal to $4.2 \%$ resulted in a maximum pit depth of about $0.5 \mathrm{~mm}$; on the other hand, for the cracked concrete a mass loss equal to about $12.6 \%$ corresponded to a maximum pit depth of $1.2 \mathrm{~mm}$. The pitting factor " $R$," that is, the ratio of maximum pit depth to average corrosion penetration depth, was, respectively, equal to 4.4 and 5.9 for cracked and uncracked condition. In the same study r.c. samples with different compositions were continuously submerged in natural sea water for six years. Mass losses were found in the order of $20 \%$ and the corresponding pit depth values were between $1.15 \mathrm{~mm}$ and $2.50 \mathrm{~mm}$, with related $R$ values between 2.7 and 5.3 .
These results indicate that, for the same level of mass loss, the $R$ values are higher for increasing quality concrete and for uncracked concrete, with respect to cracked condition. This has been confirmed by results published in [38]: the maximum $R$ value decreased significantly from 10 to 2 with increasing average cross-sectional loss, between $2 \%$ to $16 \%$. Furthermore, as visible from Figure 10, the scatter of the pit depth results is more significant for embedded samples than for the bare samples in salt spray chamber test, with values between 2 and 20 and lower than 2, respectively, for embedded samples and salt spray chamber tests.

From what is herein presented, it is clear that the salt spray test results are not usually representing the "natural" chloride induced corrosion of rebars in concrete. The local attack expressed by pitting factor, especially in the case of uncracked concrete where critical chloride content at the rebar surface is just reached, cannot be simulated well with salt spray testing. The pitting factor $R$ in salt spray tests with bare samples is significantly lower for the same mass losses: this phenomenon then represents more the uniform corrosion due to carbonation of concrete and perhaps an overlap of carbonation and chloride induced corrosion at high chloride contents. It is consequently evident that in salt spray testing the relation between anodic and cathodic surface area is higher than for chloride induced corrosion in concrete especially for the case that the critical chloride content is just reached. 

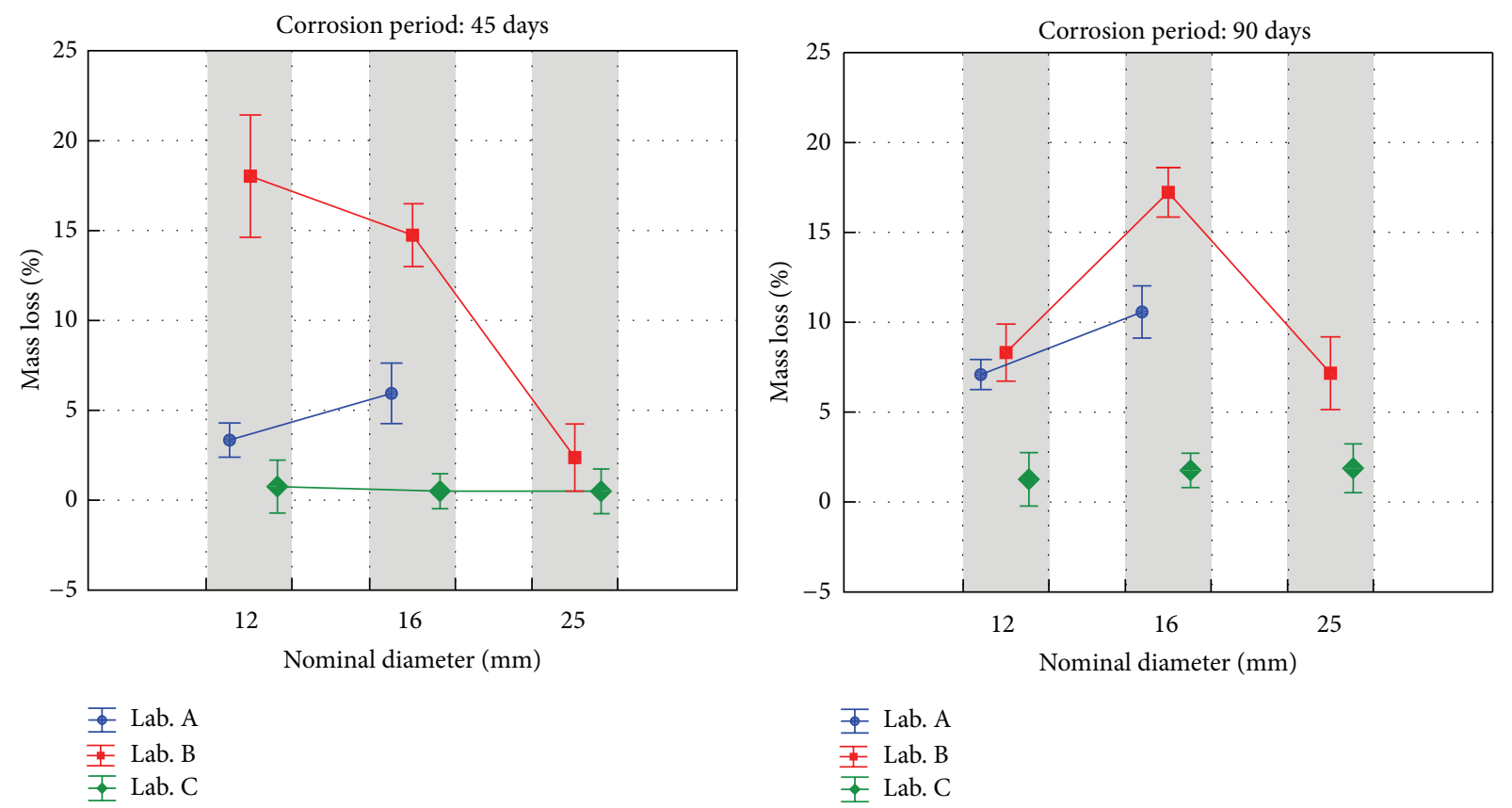

(a)
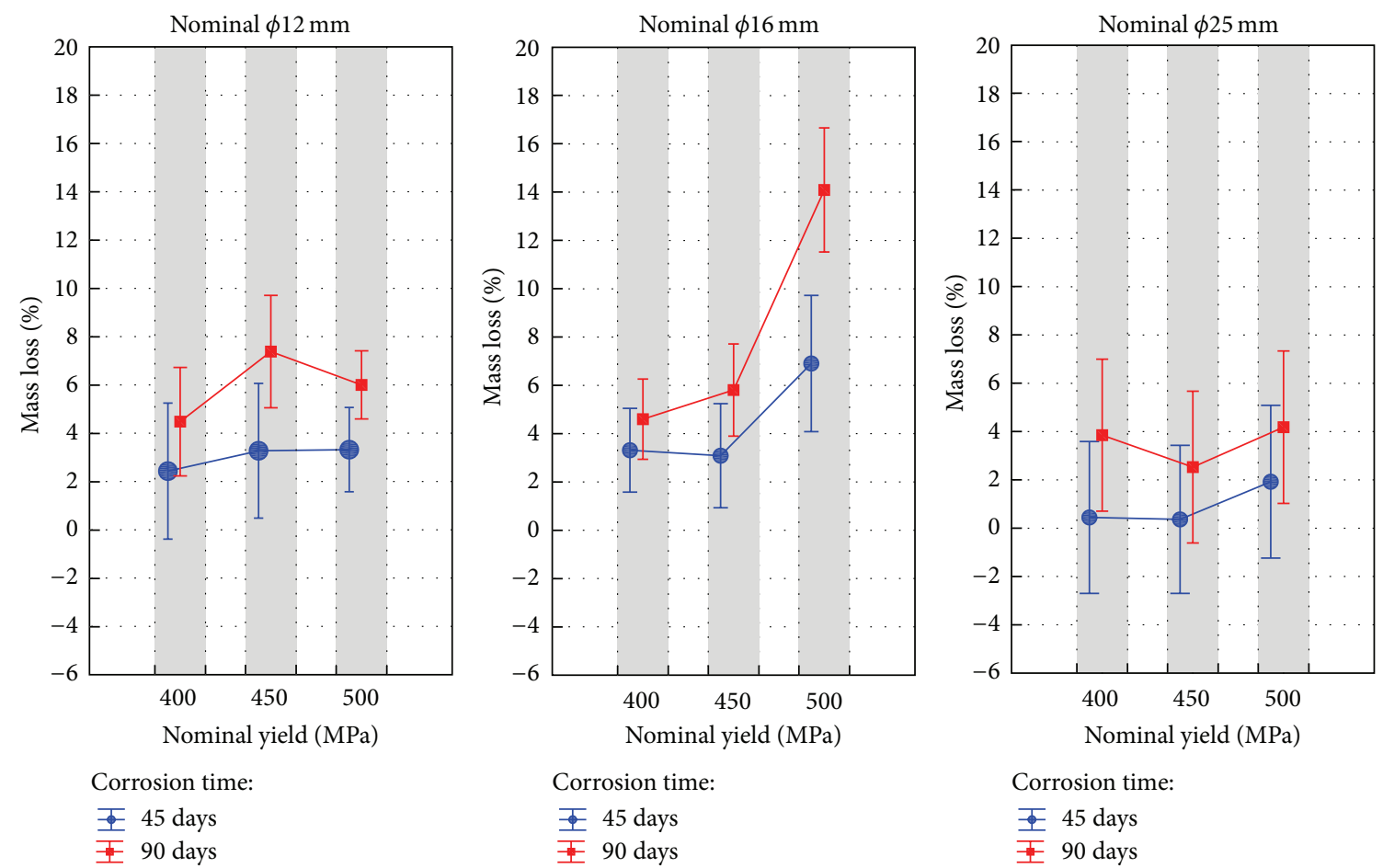

(b)

FIGURE 6: (a) ANOVA for the independent parameters Institute, nominal diameter, and corrosion time on mass loss, (b) ANOVA for the independent parameters nominal yield strength, nominal diameter, and corrosion time on mass loss.

4.3. CDI Hydrogen Absorption. For all tested reinforcing steel bars hydrogen absorption was evident. Not clear was, on the other hand, whether $\mathrm{H}_{2}$ concentration was only diffusible or diffusible and trapped. The hydrogen concentration found in the tested specimens after 90 days of exposure in salt spray chamber ranged from 0.1 to $1.0 \mathrm{ppm}$ (Figure 11(a)). No significant influence of mass loss on hydrogen concentration was observed.

The statistical analysis adopting ANOVA technique did not evidence the influence of type of production, ductility 

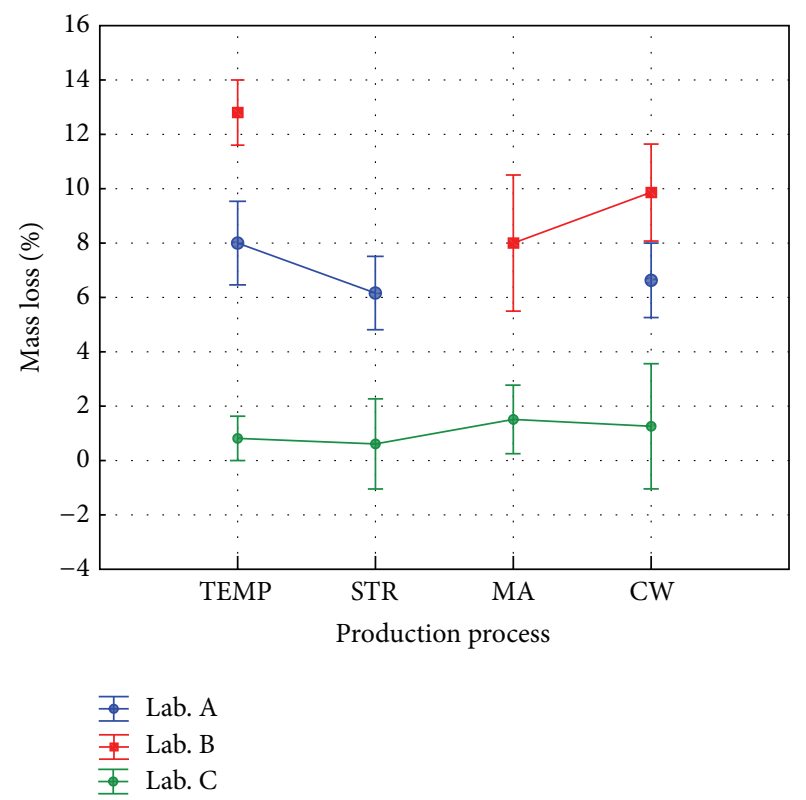

Figure 7: ANOVA for the independent parameters Institute and production type on mass loss.

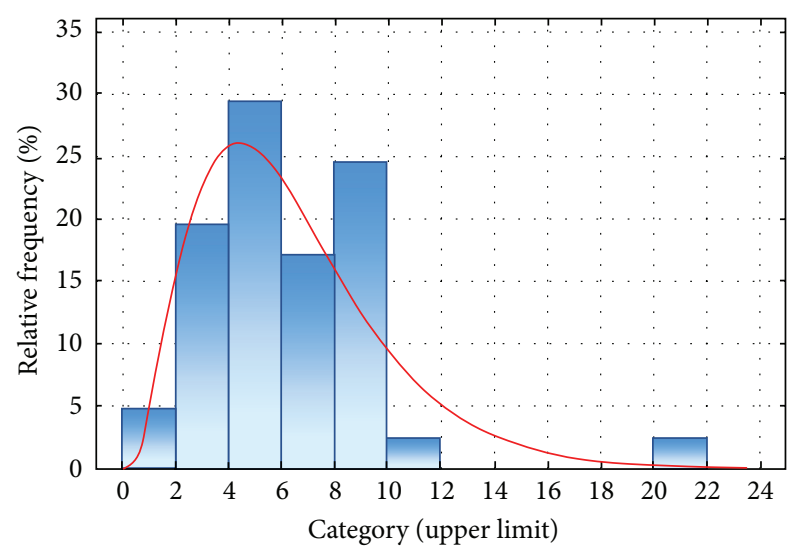

FIGURE 8: Gamma distribution for mass loss.

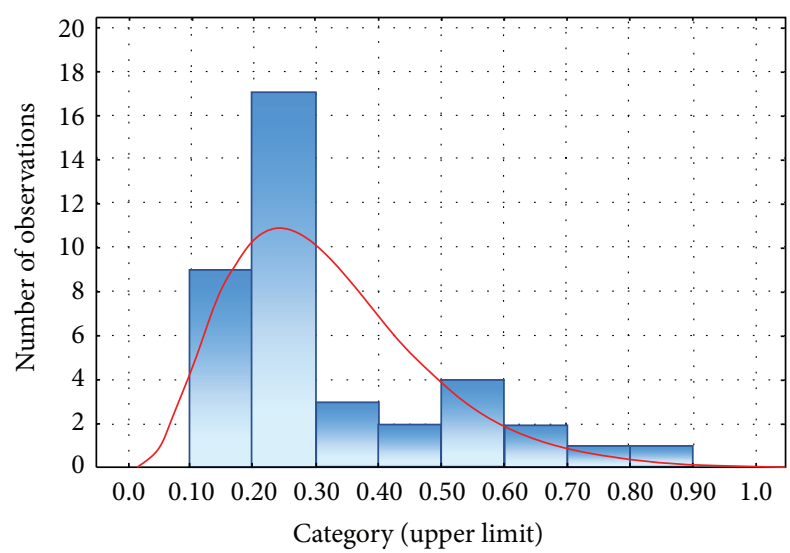

FIGURE 9: Distribution of pit depth for an embedded sample with a mass loss of $2.23 \%$.

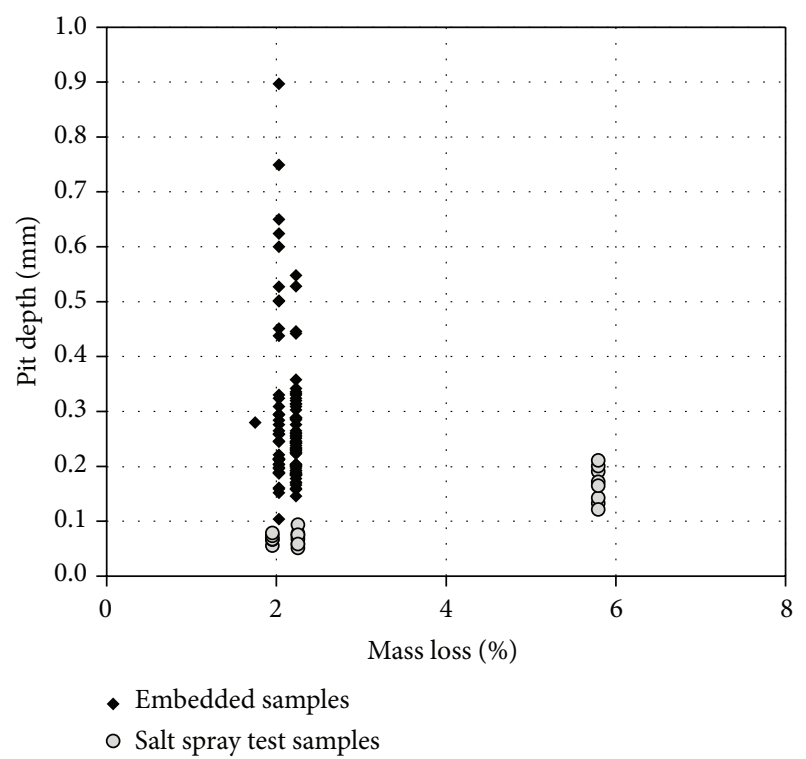

Figure 10: Pit depth depending on mass loss for embedded samples and salt spray samples.

class, and nominal yielding strength on the hydrogen absorption; this was probably due to the reduced amount of data available and to the following evident scatter of hydrogen concentration.

Also the influence of nominal diameter $\left(d_{\text {nom }}\right)$ was not really clear: for a nominal diameter of $25 \mathrm{~mm}$ the hydrogen concentration for the $500 \mathrm{MPa}$ nominal yield strength was significantly high, whereas in the case of the nominal yield strength of $450 \mathrm{MPa}$ no difference against smaller diameters was revealed.

As a consequence of what is presented above, the hypothesis of no significant difference among all the obtained data was assumed. In this way, it was possible to evaluate all mass loss values and all hydrogen concentration values as one single population. Both populations were approximated with gamma distributions; for example, in Figure 11(b) the gamma distribution for $\mathrm{H}_{2}$ concentration is presented.

For a "mean" mass loss value of 6\% (i.e., pit depth equal to $0.15 \mathrm{~mm}$ ) a "mean" hydrogen concentration due to corrosion of about $0.3 \mathrm{ppm}$ was finally assumed on the base of executed investigations.

This value, anyway, appeared very high if compared to the calculation of $\mathrm{H}_{2}$-activity derived from literature, as briefly summarized in Table 5. The results of the hydrogen content measurements obtained from experimental tests executed inside Rusteel project [5] ${ }^{1}$ were at least three times higher than the ones determined for practical conditions in exposure class XS2 according to actual literature [23, 39]; this fact was probably related to the very aggressive conditions represented during tests in salt spray chamber. As a consequence, it can be concluded that hydrogen concentration is usually lower than the values directly obtained from accelerated corrosion tests and, according to literature survey, not relevant for the mechanical performance of reinforcing steels, because 


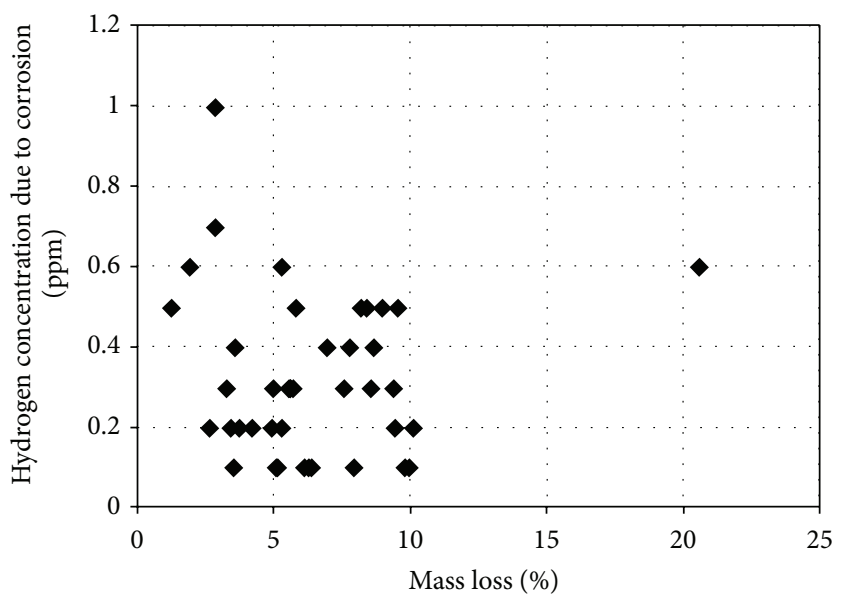

(a)

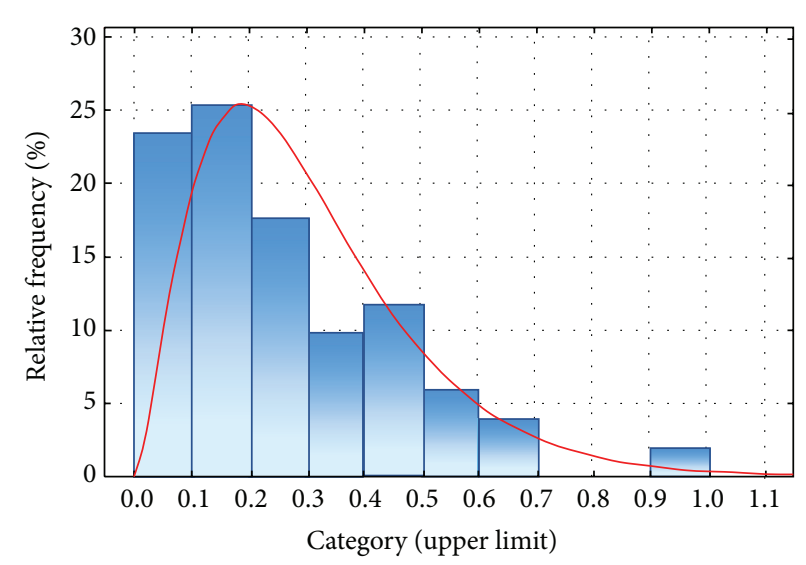

(b)

Figure 11: (a) Hydrogen concentration due to corrosion for salt spray samples (90 days of exposure). (b) Gamma distribution for hydrogen concentration.

according to Figure 11(a) a hydrogen content of less than $0.3 \mathrm{ppm}$ has no significant impact on mechanical performance of rebars with yield strengths at about $500 \mathrm{MPa}$.

\section{Correlation of CDIs and PIs for Static and Cyclic Conditions}

5.1. Static Performance Correlation of Relevant PIs to CDI. All the measured mechanical performance characteristics for static loading condition after corrosion (yield strength $R_{e \text {,corr }}$, tensile strength $R_{m \text {,corr }}$, hardening ratio $\left(R_{m} / R_{e}\right)_{\text {corr }}$, strain at maximum load $A_{\text {gt,corr }}$, and necking strain $Z_{\text {corr }}$ ) were related to the one evaluated in the "reference" conditions, for example, in terms of residual percentage $A_{\mathrm{gt}}=100 A_{\mathrm{gt}, \mathrm{corr}} / A_{\mathrm{gt}, 0}$. The mean values differentiated by laboratory were used: this was executed to eliminate influences from nominal yield, nominal diameter, and ductility class in order to compare more data.

The most important Performance Indicator (PI) for static loads was, finally, strain at maximum load $\left(A_{\mathrm{gt}}\right)$ : a strong reduction of $A_{\mathrm{gt}}$ was observed already in presence of reduced mass losses, while all the other performance characteristics did not exhibit a significant decrease with the increase of mass loss, according to what is well evidenced in $\left([5]^{1},[36,40]\right)$, simply schematized in Figure 12. For sake of clarity, no significant influence of ML on the PI $R_{m} / R_{e}$ was observable (i.e., no influence of testing laboratory, production type, ductility class, nominal yield, and nominal diameter on the result). A slight linear reduction of the PI's $R_{e}$ and $R_{m}$ with increasing ML was observed, but also in this case, no influence of testing laboratory, production type, ductility class, nominal yield, and nominal diameter on the result was detected by using ANOVA technique. Moreover, the scatter of results was, in general, reasonable.

A further ANOVA analysis on influencing parameters affecting the PI residual $A_{\mathrm{gt}}$ has led to the following results: one significant influence was represented by the testing laboratory. Reason for this is the difference in salt spray test results on mass loss already discussed before. Another significant factor on the result is the nominal diameter. With increasing diameter the PI residual $A_{\text {gt }}$ decreases less importantly with mass loss (see Figure 13). The parameters ductility class and production type are playing only a minor role. There is only the tendency that with increasing ductility the reduction of residual $A_{\mathrm{gt}}$ decreases less importantly with mass loss. The decrease of residual $A_{\mathrm{gt}}$ decreases less importantly with mass loss in the order of MA (microalloyed), TEMP (TempCore), and STR (stretched). It needs to be taken into account that nominal diameter, ductility class, and production type are partly linked parameters and not totally independent parameters.

Due to the result that diameter has a significant influence on residual $A_{\mathrm{gt}}$, the full set of data was separated into two groups: less equal diameter $16 \mathrm{~mm}$ and diameter $25 \mathrm{~mm}$. For both groups quantile values and mean values were calculated and are indicated in Figure 14. Whereas for diameter $\leq 16 \mathrm{~mm}$ the mean value for residual $A_{\mathrm{gt}}$ is at a mass loss of $5 \%$ at about $50 \%$, it is for diameter $25 \mathrm{~mm}$ at about $85 \%$. Similar results for residual $A_{\mathrm{gt}}$ were obtained in [40] for embedded samples in accelerated corrosion tests. Rebars with a diameter of $19.1 \mathrm{~mm}$ were embedded in concrete samples which had been placed in chloride containing sand with sufficient humidity. To accelerate corrosion a constant electrical potential of $10 \mathrm{~V}$ was applied which resulted in very high corrosion current densities between 50 and $250 \mu \mathrm{A} / \mathrm{cm}^{2}$. In [37] pitting factors for current densities in between 10 and $100 \mu \mathrm{A} / \mathrm{cm}^{2}$ were found between 6 and 16, which correspond quite well to natural chloride induced corrosion. This leads to the assumption that the results on mechanical performance characteristics obtained in salt spray testing can be used to qualify the residual performance of rebars after corrosion for carbonation induced corrosion but also for chloride induced corrosion with higher mass losses from $5 \%$ onwards. 


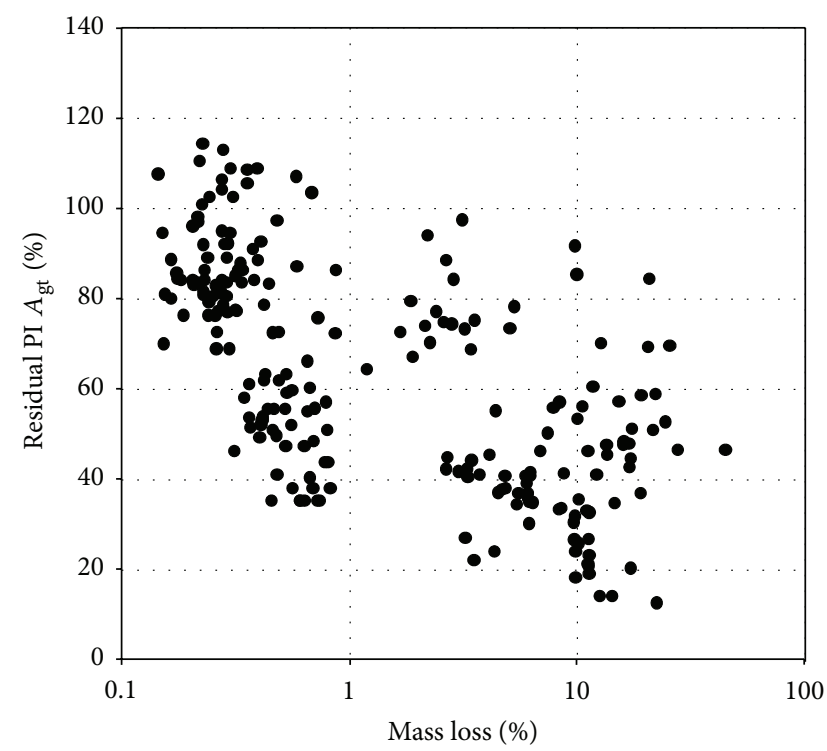

(a)

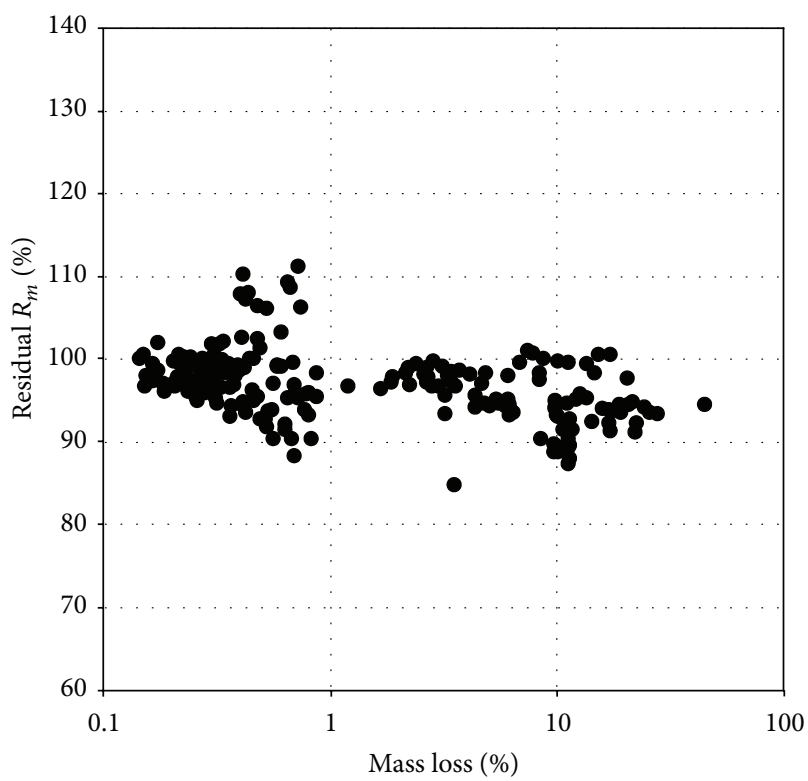

(c)

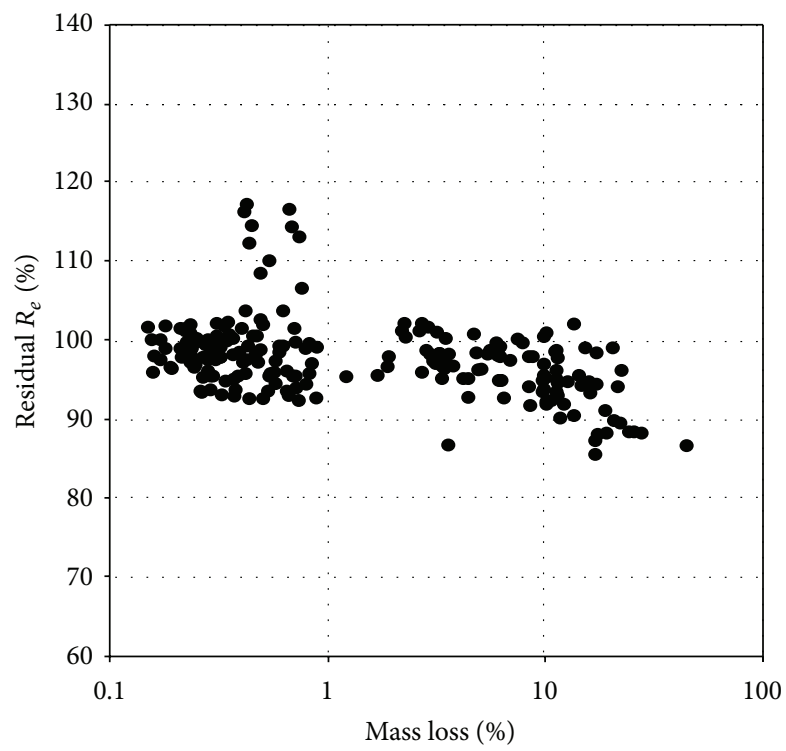

(b)

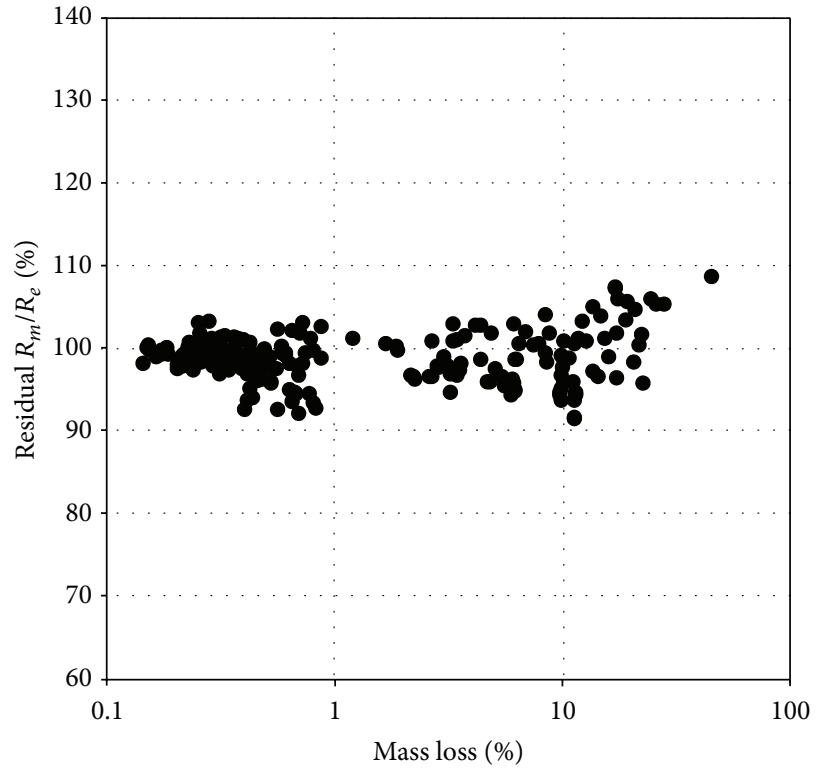

(d)

FIGURE 12: Representation of the trend of (a) residual elongation at maximum load $\left(A_{\mathrm{gt}}\right)$, (b) residual yielding strength $\left(R_{e}\right)$, (c) residual tensile strength $\left(R_{m}\right)$, and $(\mathrm{d})$ residual hardening ratio $\left(R_{m} / R_{e}\right)$ towards obtained values of mass loss.

5.2. Low-Cycle Fatigue Performance Correlation of Relevant PIs to CDI. The assumed PIs for low-cycle fatigue tests after corrosion in salt spray chamber were the dissipated energy (dE) for the cumulated number of load cycles till fracture of the sample (or till the stop of the test) and the number of cycles $(N)$ till fracture (or till the stop of the test).

The results of the experimental tests' campaign evidenced that the most significant parameters affecting the number of cycles and the dissipated energy were, respectively, the imposed testing strain $(\Delta \varepsilon)$ and the free length of the specimens $\left(L_{0}\right)$. The influence of corrosion on low-cycle fatigue PIs was visible but not very significant, due to the large scattering of mass loss values coming from salt spray chamber tests. No influence was detectable for the other independent parameters such as nominal yield, nominal diameter, ductility class, and production type.

In order to evaluate in an efficient way the role of corrosion on the cyclic behaviour of bars, statistical analyses were repeated neglecting the influence of strain and free length of the specimens. This was possible via specified values for $\mathrm{dE}$ and $N$, allowing making the residual dissipated energy $(100 *$ $\left.\left(\mathrm{dE}_{\mathrm{corr}} / \mathrm{dE}_{0}\right)[\%]\right)$ and the specified number of load cycles 


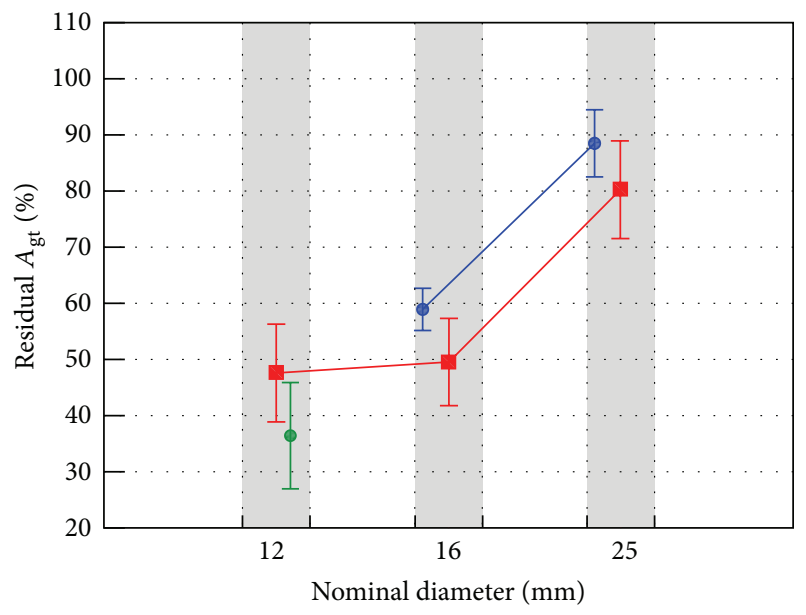

Doctility class A
Ductility class B
D- Ductility class C

(a)

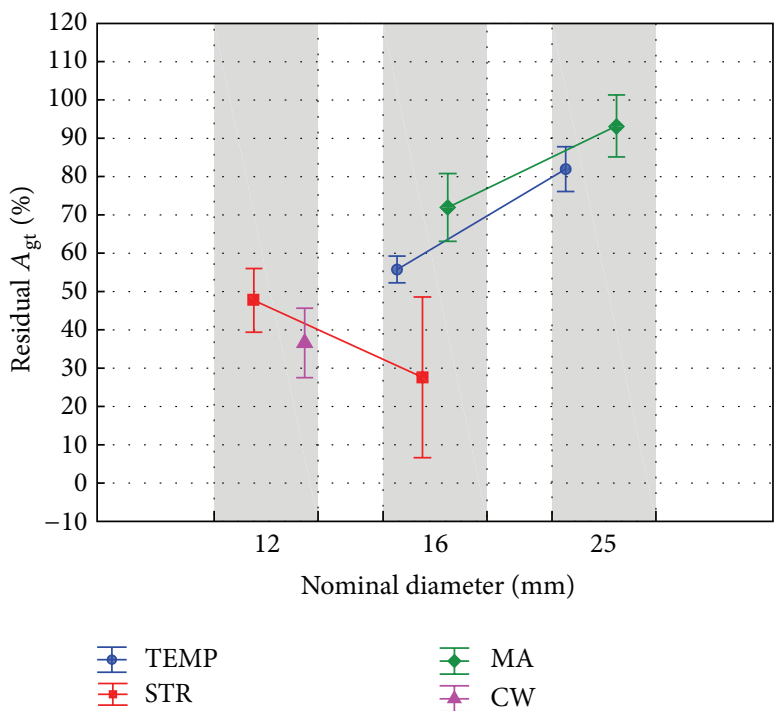

(b)

FIGURE 13: Influence of (a) ductility class and nominal diameter and (b) production type and nominal diameter on residual $A_{\mathrm{gt}}$.

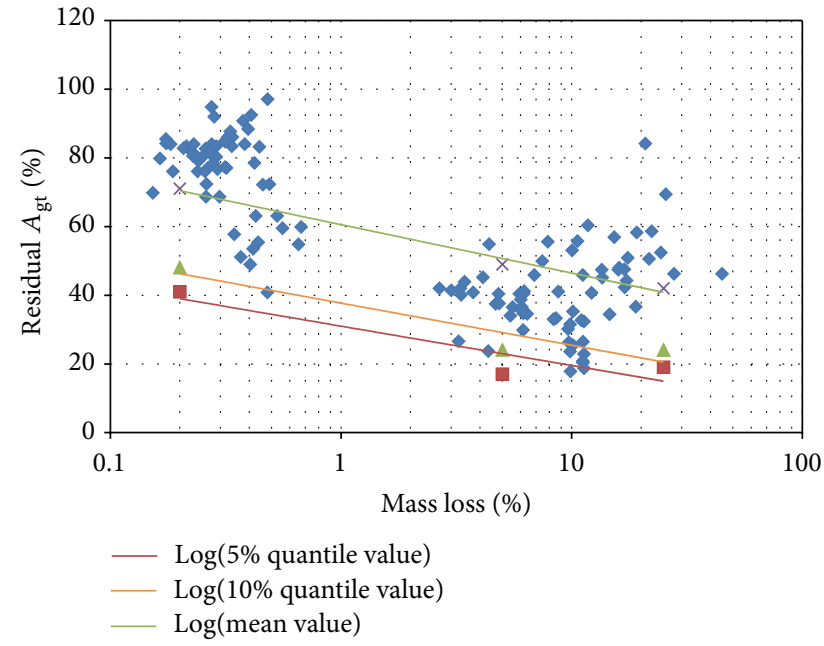

(a)

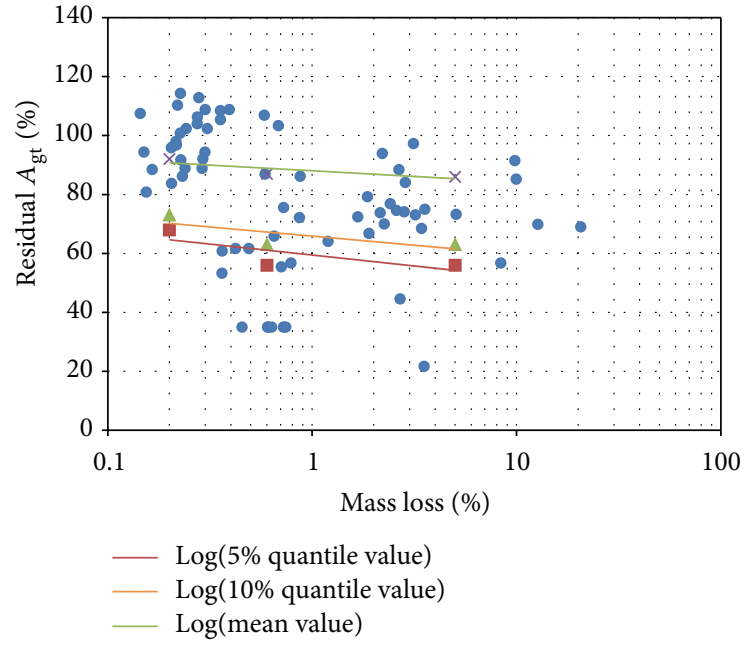

(b)

Figure 14: (a) Influence of mass loss on residual $A_{\mathrm{gt}}$ for nominal diameter $16 \mathrm{~mm}$ (5\%, 10\%, and $50 \%$ quantile). (b) Influence of mass loss on residual $A_{\mathrm{gt}}$ for nominal diameter $25 \mathrm{~mm}(5 \%, 10 \%$, and $50 \%$ quantile).

$\left(\left(N_{\text {corr }} / N_{0}\right)[-]\right)$ independent of strain and free test length. As a consequence of this practical operation, it was observed that both PI's res. $N$ and res.dE were strongly influenced by corrosion. In order to estimate the PI's res. $N$ and res.dE as a function of mass loss, the following approximations were also made:

(i) Normal distribution of mass loss in a range between 0 and $5 \%$ and between 5 and $10 \%$.

(ii) Normal distributions of res. $N$ and res.dE in the abovementioned mass loss ranges.
With these approximations, the $5 \%$ and $10 \%$ quantile values for res. $N$ and res.dE were calculated and implemented at the mean value for mass loss in the predefined mass loss range: for example, for a mass loss range from $5 \%$ to $10 \%$, the mean value for mass loss is equal to $7.41 \%$ and the $5 \%$ quantile value for res.dE is equal to $48.79 \%$.

The full set of data is provided by Table 6 and simply represented in Figure 15. The PI's res. $N$ and res.dE decreased more or less in the same slope with mass loss; a strong decrease for values of mass loss lower than $5 \%$ was followed by 
TABLE 6: Evaluation of quantile values.

\begin{tabular}{|c|c|c|c|c|}
\hline Mass loss range [\%] & Statistical value & Mass loss [\%] & res.N [-] & res.dE [\%] \\
\hline \multirow{5}{*}{0} & Mean & 0.00 & 1.01 & 99.80 \\
\hline & Standard deviation & 0.00 & 0.07 & 6.24 \\
\hline & Variation coefficient & 0.00 & 7.29 & 6.25 \\
\hline & $5 \%$ quantile & 0.00 & 0.89 & 89.53 \\
\hline & $10 \%$ quantile & 0.00 & 0.91 & 91.80 \\
\hline \multirow{5}{*}{$0<\mathrm{ML} \leq 5$} & Mean & 3.39 & 0.81 & 81.04 \\
\hline & Standard deviation & 0.95 & 0.15 & 15.08 \\
\hline & Variation coefficient & 28.04 & 17.93 & 18.61 \\
\hline & $5 \%$ quantile & 1.83 & 0.57 & 56.23 \\
\hline & $10 \%$ quantile & 2.17 & 0.63 & 61.71 \\
\hline \multirow{5}{*}{$5<\mathrm{ML} \leq 10$} & Mean & 7.41 & 0.78 & 77.08 \\
\hline & Standard deviation & 1.36 & 0.18 & 17.20 \\
\hline & Variation coefficient & 18.39 & 22.93 & 22.31 \\
\hline & $5 \%$ quantile & 5.17 & 0.48 & 48.79 \\
\hline & $10 \%$ quantile & 5.66 & 0.55 & 55.03 \\
\hline
\end{tabular}

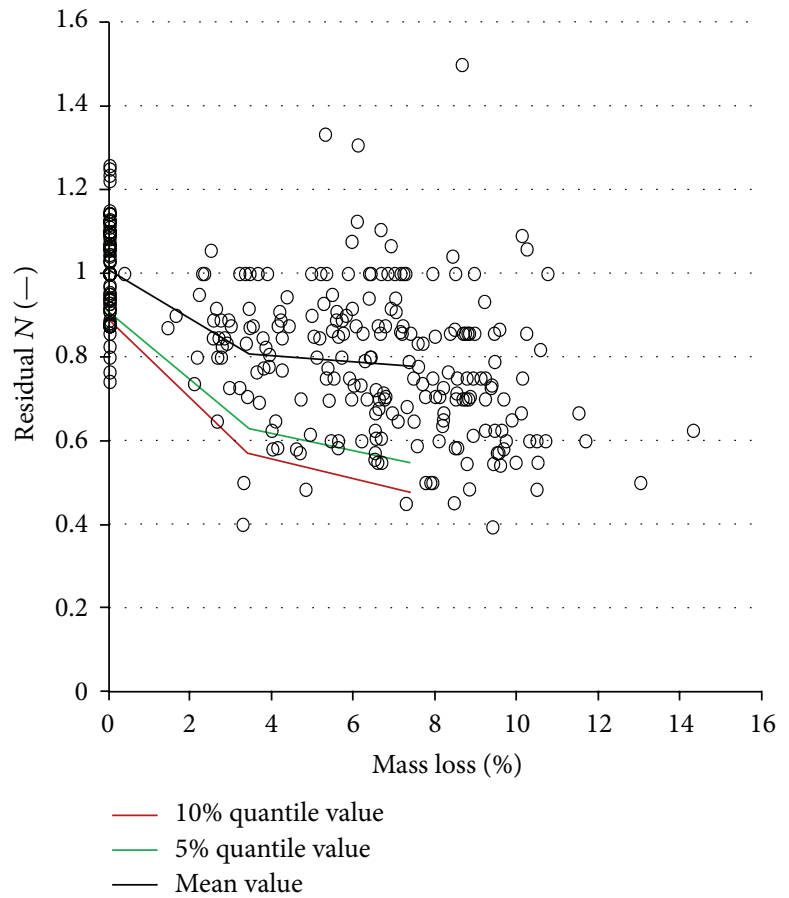

(a)

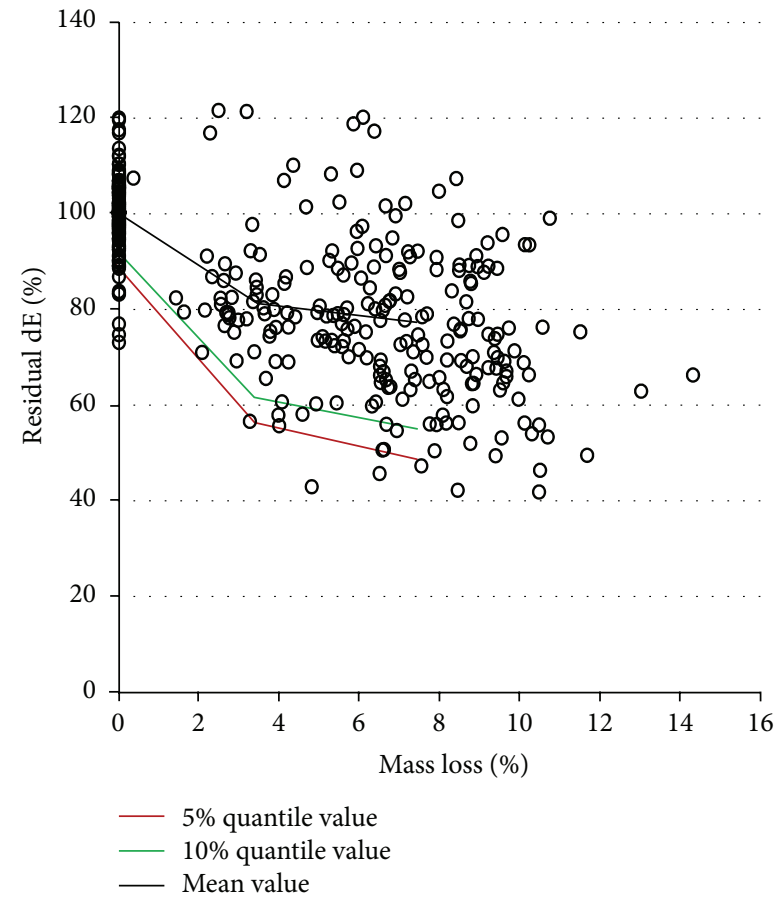

(b)

FiguRE 15: (a) Scatterplot for res.N versus mass loss and quantile slopes for res.N. (b) Scatterplot for res.dE versus mass loss and quantile slopes for res.dE.

a flat slop for values higher than $5 \%$. The residual performance for $8 \%$ mass loss was approximately equal to $50 \%$.

\section{Relation of Practical Exposure Classes to Corrosion Rates}

The corrosion process of reinforcing steel in concrete is divided into two periods (Figure 16(a)): the initiation period $\left(t_{\text {in }}\right)$, that is, the time before the onset of corrosion, and the propagation period $\left(t_{p}\right)$.

During the initiation period, the carbonation front is moving towards the steel surface or the chloride concentration is rising to its critical value; the duration of $t_{\text {in }}$ is strongly influenced by concrete performance and exposure conditions: a large amount of detailed information is required, for each single building, to predict the initiation period. 


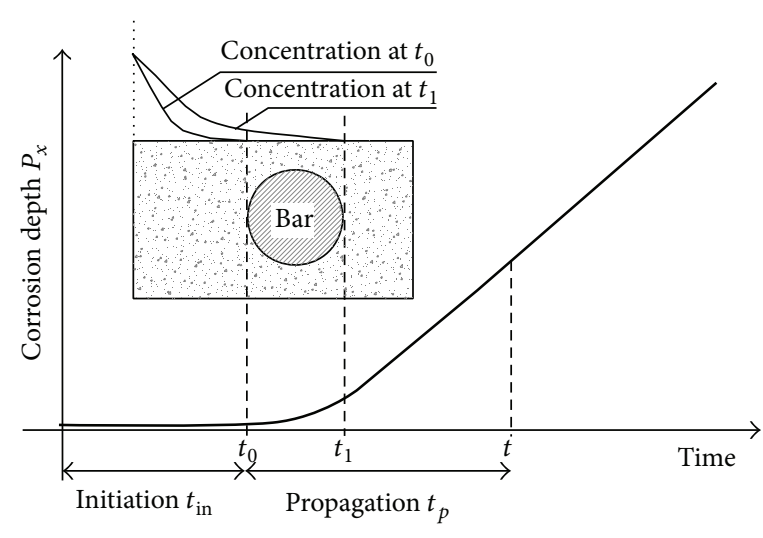

(a)

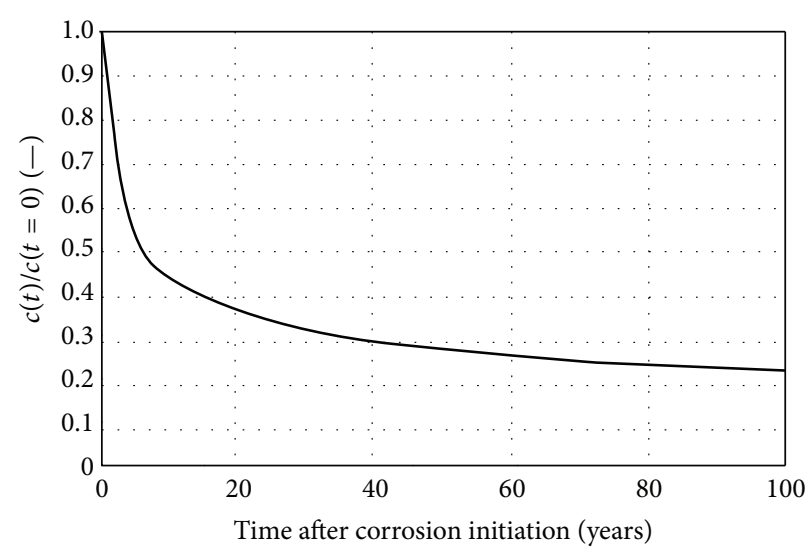

(b)

Figure 16: (a) Corrosion process over time. (b) Development of corrosion rate over time.

After critical corrosion conditions at the surface of the reinforcing steel are fulfilled, propagation period $\left(t_{p}\right)$ starts with the initiation of corrosion. The classification of the corrosion phenomena in the propagation period (according to what is presented in Table 1 for XC1 and XS1, also evaluable for other exposure classes, as shown in $[5]^{1}$ ) relates practical exposure classes to corrosion rates and hydrogen activity.

For example, the adoption of (1) and (2) allows the correlation between the values of mass loss (corrosion rates in $\mu \mathrm{m} /$ year) and corrosion periods, as function of current densities:

$$
c=\frac{V \cdot I \cdot t}{z \cdot F}
$$

" $c$ " being the corrosion rates (in $\mu \mathrm{m} /$ year), " $V$ " the molar volume of iron, "I" the current (in A), " $t$ " the time (in sec), " $z$ " the number of electrons, and " $F$ " Faraday's constant.

The relation between current densities and erosion rates can be then derived, according to what is presented in Table 7 . The adopted values of the current densities for the different exposure classes are suggested by Rodriguez et al. [24]; the calculated erosion rates are in good agreement with the results shortly presented in Table 1 and reported in Apostolopoulos et al. [5] ${ }^{1}$.

After corrosion initiation, the knowledge of the development of the corrosion rates over time is required for the evaluation of mass loss. Vu and Stewart [39] provided the trend of the corrosion current density over time (2) in the good case of normal corrosion evolution:

$$
i_{\text {corr }(t)}=i_{\text {corr }(1)} \cdot 0.85 \cdot t^{-0.29},
$$

" $i_{\text {corr }(t)}$ " being the current density during the propagation period $\left(\mu \mathrm{A} / \mathrm{cm}^{2}\right)$, " $i_{\text {corr(1) }}$ " the current density at the initiation time $\left(\mu \mathrm{A} / \mathrm{cm}^{2}\right)$, and " $t$ " the time.

Figure 16(b) shows the development of the specified corrosion rate $c(t) / c\left(t_{0}\right)$ over the corrosion time: after a corrosion period of about 10 years the curve converges to a residual corrosion rate equal to about $20 \%$ of the one evaluated immediately after corrosion initiation.
TABLE 7: Ranges for corrosion rates related to exposure classes immediately after corrosion initiation $\left(i_{\text {corr }, t=0}\right)$ [24].

\begin{tabular}{lcc}
\hline Exposure class & $\begin{array}{c}\text { Corrosion current } \\
\text { density } i_{\text {corr }}\left[\mu \mathrm{A} / \mathrm{cm}^{2}\right]\end{array}$ & $\begin{array}{c}\text { Corrosion rate } \\
{[\mu \mathrm{m} / \text { year }]}\end{array}$ \\
\hline $\mathrm{X} 0$ & $\approx 0,01$ & 0,12 \\
$\mathrm{XC1}$ & $\approx 0,01$ & 0,12 \\
$\mathrm{XC2}$ & $0.1-0.5$ & $1.16-5.80$ \\
$\mathrm{XC} 3$ & $0.05-0.2$ & $0.58-2.32$ \\
$\mathrm{XC} 4$ & $0.01-0.5$ & $0.12-5.80$ \\
$\mathrm{XD1}$ & $0.1-0.2$ & $1.16-2.32$ \\
$\mathrm{XD} 2$ & $0.1-0.5$ & $1.16-5.80$ \\
$\mathrm{XD} 3$ & $0.5-5.0$ & $5.80-58.10$ \\
$\mathrm{XS1}$ & $0.5-5.0$ & $5.80-58.10$ \\
$\mathrm{XS2}$ & $0.1-1.0$ & $1.16-11.60$ \\
$\mathrm{XS3}$ & $1.0-10.0$ & $11.6-1160$ \\
\hline
\end{tabular}

\section{Correlation of PIs and CDIs with Practical Corrosion Conditions}

According to the results presented in the previous paragraphs, the relevant Performance Indicators (PIs) were the percentage strain at maximum load $\left(A_{\mathrm{gt}}\right)$ and the dissipated energy $(\mathrm{dE})$ and/or the number of load cycles $(N)$ till fracture (or stop of the test), respectively, for monotonic and low-cycle fatigue conditions.

The most relevant CDI was the mass loss. The pit depths values and pitting factors obtained indicate that the results are representative at least for the corrosion phenomena as severe carbonation induced corrosion and/or corrosion in cracked concrete with severe chloride attack (wider cracks). Hydrogen concentration was not taken into account because of its minor influence.

The following example is presented as a possible approach to qualify the residual performance of rebars in concrete 
TABLE 8: Relation of CDI and PIs for practical corrosion conditions.

\begin{tabular}{|c|c|c|c|c|}
\hline $\mathrm{CDI}$ & \multicolumn{4}{|c|}{ Nominal diameter: $16 \mathrm{~mm}$} \\
\hline \multirow[b]{2}{*}{$\begin{array}{l}\text { Corrosion rate } \\
{[\mu \mathrm{m} / \text { year }]}\end{array}$} & \multicolumn{4}{|c|}{ Time in years to reach a mass loss of $5 \%$ for the following conditions } \\
\hline & \multicolumn{2}{|c|}{$\begin{array}{l}\text { Poor concrete, low concrete cover, } \\
\text { and/or cracked concrete }\end{array}$} & \multicolumn{2}{|c|}{$\begin{array}{l}\text { Uncracked concrete or only small cracks } \\
\text { together with a good concrete and a } \\
\text { sufficient concrete cover }\end{array}$} \\
\hline Low: 1.16 & \multicolumn{2}{|c|}{$>150$} & \multicolumn{2}{|c|}{$>150$} \\
\hline High: 11.6 & \multicolumn{2}{|c|}{$<20$} & \multicolumn{2}{|r|}{$<45$} \\
\hline PIs & \multicolumn{4}{|c|}{ Nominal diameter: $16 \mathrm{~mm}$} \\
\hline Mass loss [\%] & $\begin{array}{l}\text { Mean value } \\
\text { res.N [-] }\end{array}$ & $\begin{array}{l}5 \% \text { quantile value } \\
\text { res. } N[-]\end{array}$ & $\begin{array}{l}\text { Mean value } \\
\text { res.dE [\%] }\end{array}$ & $5 \%$ quantile value res.dE $[\mathrm{MPa}]$ \\
\hline 5.0 & 0.8 & 0.55 & $80 \%$ & $55 \%$ \\
\hline Mass loss [\%] & \multicolumn{2}{|c|}{ Mean value res. $A_{\mathrm{gt}}[\%]$} & \multicolumn{2}{|c|}{$5 \%$ quantile value res. $A_{\mathrm{gt}}[\%]$} \\
\hline 5.0 & \multicolumn{2}{|c|}{50} & & 25 \\
\hline
\end{tabular}

structures which are subjected to aggressive corrosion conditions. The relation of CDI in laboratory tests to practical corrosion conditions could be then estimated on the basis of common literature results to practical corrosion rates [24] and presented in the previous paragraphs. For each exposure condition and concrete strength, concrete cover, and crack width, the corrosion rate could be then estimated: using (1) and (2) it is possible to determine, for each predefined mass loss in salt spray test, the duration in practice when the mass loss is reached under practical conditions. The mass loss in salt spray testing could be related to the residual mechanical performance for static and low-cycle fatigue loads. As a consequence, it is possible to qualify mechanical performance depending on the degree of corrosion.

As an example, for a reinforced concrete building component in exposure condition XS2 a mass loss of 5\% can be reached for a high corrosion rate in combination with a sufficient concrete cover thickness after, approximately, 45 years. The related 5\% quantile values for res. $N /$ res.dE and for res. $A_{\mathrm{gt}}$ were, respectively, approximately $55 \%$ and $25 \%$ (Table 8 ).

In a more simple way, the $95 \%$ of the reinforcing steel in this building component in the defined condition will provide probably at least a residual $N / \mathrm{dE}$ of $55 \%$ and a residual $A_{\mathrm{gt}}$ of $25 \%$. For a reinforcing steel with an initial $A_{\mathrm{gt}}$ of $10 \%$, the residual performance res. $A_{\mathrm{gt}}$ after a mass loss of $5 \%$ is about $2.5 \%$ and it will sustain at least 10 load cycles at a strain of $2.5 \%$. This estimation can be repeated for each exposure condition according to EN 1992-1-1:2005 and concrete strength, concrete cover, and crack width.

\section{Conclusions}

In the present work the results of a statistical analysis executed on the experimental data of tensile and low-cycle fatigue tests on a wide range of corroded steel reinforcing bars are presented, evidencing the correlation between Performance Indicators (PIs) and Corrosion Damage Indicators (CDIs).

Results were presented with reference to the PI's $A_{\mathrm{gt}}$ and dissipated energy or number of cycles to failure for, respectively, the monotonic and cyclic behaviour of reinforcements, and in relation to the CDI mass loss obtained in salt spray testing on bare samples. This type of accelerated corrosion test was used to study the high number of test samples in due time. The corrosion phenomena obtained in salt spray testing deviate significantly from corrosion phenomena (pitting factor) obtained in practical conditions. Salt spray testing represents practical conditions for the more uniform corrosion as a result of a severe carbonation of the concrete and/or for higher chloride contents at the surface of the rebar. At low corrosion current densities the effect of pit depth on residual mechanical performance might be underestimated.

The most important effect of corrosion phenomena was evidenced in the case of monotonic behaviour (i.e., PI residual $A_{\mathrm{gt}}$ ), while the ductility capacity related to the cyclic behaviour (i.e., PI dissipated energy and/or number of cycles) was generally less affected by the effects of corrosion in terms of mass loss.

As a consequence of what is presented concerning the relationship between Corrosion Damage Indicators (CDIs) and Performance Indexes (PIs), engineers and designers are enabled to estimate residual mechanical performance depending on the degree of corrosion expressed through mass loss, a value which can easily be determined with an acceptable accuracy.

In order to fully satisfy the seismic ductile requirements in exposure conditions with significant corrosion rates (i.e., $\mathrm{XC} 2$ to $\mathrm{XC} 4, \mathrm{XD} 2$ and XD3, XS1 to XS3) and to prevent damage due to aggressive environmental conditions with the following degradation of the mechanical properties, additional indications, completing and improving what is already presented in Eurocodes, were suggested, such as the adoption of higher strength concrete (at least one class) or, in a similar way, the design of concrete cover with the same concrete strength but concrete cover with higher thickness (increase by $5.0 \mathrm{~mm}$ or more). Obviously, in the case of very aggressive environmental conditions, additional measures like, for example, the coating of the surface of concrete, cathodic protection, could be proposed.

The statistical analysis executed using ANOVA technique also evidenced that the influence of corrosion, in terms of mass loss, on the decrease of the elongation to maximum load generally decreased with the increase of the diameter (i.e., 
for higher diameters the effects of corrosion on the $A_{\mathrm{gt}}$ were lower). As a consequence, despite an accurate analysis of the effects of large diameter for what concerns the bond condition between steel and concrete, probably the adoption of higher diameters can be suggested (e.g., for a required reinforcement of $24 \mathrm{~cm}^{2}$ the use of 8 bars $\phi 20 \mathrm{~mm}$ instead of 12 bars $\phi 16 \mathrm{~mm}$ ). Obviously, higher initial values of ductility (in terms of $A_{\text {gt }}$ ) were associated with higher residual values after corrosion attack: this was evidenced, for example, in the case of microalloyed steel, for both 16 and $25 \mathrm{~mm}$ diameters [5] ${ }^{1}$.

\section{Conflict of Interests}

The authors declare that there is no conflict of interests regarding the publication of this paper.

\section{Acknowledgments}

The present work was developed inside the European Research Project Rusteel "Effects of Corrosion on Low-Cycle Fatigue (Seismic) Behaviour of High Strength Steel Reinforcing Bars" (RFSR-CT-2009-00023), funded by the Research Fund for Coal and Steel (RFCS). The authors would like to thank all the partners involved in the project for their contributions.

\section{Endnotes}

1. The complete database of experimental tensile and lowcycle fatigue tests can be directly downloaded at: http:// bookshop.europa.eu/en/effects-of-corrosion-on-lowcycle-fatigue-seismic-behaviour-of-high-strength-steelreinforcing-bars-rusteel--pbKINA26687/.

\section{References}

[1] EN, "Eurocode 8-design of structures for earthquake resistance-part 1: general rules, seismic actions and rules for buildings," EN 1998-1, 2005.

[2] Ministero delle Infrastrutture, NormeTecniche per le Costruzioni, D. Min. Inf. 14 gennaio 2008, Gazzetta Ufficiale no. 29 of February 4th 2008-Supplemento Ordinario no. 30, 2008 (Italian).

[3] FEMA 356, Pre-Standard and Commentary for the Seismic Rehabilitation of Buildings, Federal Emergency Management Agency, Washington, DC, USA, 2000.

[4] UNI, "Eurocode 2 (Annex C) - design of concrete structurespart 1-1: general rules and rules for buildings," UNI EN 1992-11:2005, 2005.

[5] C. Apostolopoulos, C. Ascanio, L. Bianco et al., "Effects of corrosion on low-cycle fatigue (seismic) behaviour of high strength steel reinforcing bars," Final Report RFSR-CT-200900023 project, European Commission, Brussels, Belgium, 2014.

[6] UNE, "Norma Espanõla experimental 2000-barras corrugadas de acero soldable con caracteristìcas especiales de ductilidad para armaduras de horigòn armado," UNE 36065 EX:2000, 2000 .

[7] LNEC, "Varoes de aço A400 NR de ductilidade especial para armaduras de betão armado: caracteristìcas, ensaios e marcação," LNEC E455-2008, 2008.
[8] J. Brown and S. K. Kunnath, "Low-cycle fatigue failure of reinforcing steel bars," ACI Materials Journal, vol. 101, no. 6, pp. 457-466, 2004.

[9] J. B. Mander, F. D. Panthaki, and A. Kasalanati, "Low-cycle fatigue behavior of reinforcing steel," Journal of Materials in Civil Engineering, vol. 6, no. 4, pp. 453-468, 1994.

[10] P. Crespi, Monotonic and cyclic behaviour of rebars in the plastic hinge of r.c. beams [Ph.D. thesis], 2002.

[11] R. A. Hawileh, J. A. Abdalla, F. Oudah, and K. Abdelrahman, "Low-cycle fatigue life behaviour of BS 460B and BS B500B steel reinforcing bars," Fatigue \& Fracture of Engineering Materials \& Structures, vol. 33, no. 7, pp. 397-407, 2010.

[12] M. E. Rodriguez, J. C. Botero, and J. Villa, "Cyclic stressstrain behavior of reinforcing steel including effect of buckling," Journal of Structural Engineering, vol. 125, no. 6, pp. 605-612, 1999.

[13] European Committee for Standardization (CEN), "Steel for the reinforcement of concrete-weldable reinforcing steel-general," EN 10080:2005, European Committee for Standardization (CEN), 2005.

[14] prEN, "Steel for the reinforcement of concrete-weldable reinforcing steel-general," prEN 10080, ECISS/TC-104/WG1, 2012.

[15] European Commission, M/115 Rev.1 EN, Revised Mandate M115 to CEN/CENELEC Concerning the Execution of Standardization Work for Harmonized Standards on Reinforcing and Prestressing Steels (for Concrete), European Commission, Brussels, Belgium, 2009.

[16] C. A. Apostolopoulos and D. Michalopoulos, "Effect of corrosion on mass loss, and high and low cycle fatigue of reinforcing steel," Journal of Materials Engineering and Performance, vol. 15, no. 6, pp. 742-749, 2006.

[17] C. A. Apostolopoulos and V. G. Papadakis, "Consequences of steel corrosion on the ductility properties of reinforcement bar," Construction and Building Materials, vol. 22, no. 12, pp. 23162324, 2008.

[18] M. Al Hashemi, M. De Sanctis, W. Salvatore, and R. Valentini, "Effects of corrosion induced damages on the tensile and fatigue properties of concrete reinforcing bars," in XII Convegno ANIDIS L'Ingegneria Sismica in Italia, Pisa, Italy, June 2007.

[19] A. A. Almusallam, "Effect of degree of corrosion on the properties of reinforcing steel bars," Construction and Building Materials, vol. 15, no. 8, pp. 361-368, 2001.

[20] C. A. Apostolopoulos and V. P. Pasialis, "Effects of corrosion and ribs on low cycle fatigue behavior of reinforcing steel bars $\$ 400$," Journal of Materials Engineering and Performance, vol. 19, no. 3, pp. 385-394, 2010.

[21] S. Caprili and W. Salvatore, "Cyclic behaviour of uncorroded and corroded steel reinforcing bars," Construction and Building Materials, vol. 76, pp. 168-186, 2015.

[22] M. P. Papadopoulos, C. A. Apostolopoulos, N. D. Alexopoulos, and S. G. Pantelakis, "Effect of salt spray corrosion exposure on the mechanical performance of different technical class reinforcing steel bars," Materials and Design, vol. 28, no. 8, pp. 23182328, 2007.

[23] J. Moersch, Zur Wasserstoffinduzierten Spannungsrisskorrosion von Hochfesten Spannstählen-Untersuchungen zur Dauerhaftigkeit von Spannbetontragwerken, Schriftenreihe Deutscher Ausschuss für Stahlbeton, Heft 563, 2005.

[24] J. Rodriguez, L. M. Ortega, J. Casal, and J. M. Diez, "Corrosion of reinforcement and service life of concrete structures," in Proceedings of the 7th International Conference on Durability of Building Materials and Components, Stockholm, Sweden, 1996. 
[25] H. Gräfen, "Wasserstoffinduzierte rissbildung," in Grundlagenkursus Korrosion, pp. 153-178, DECHEMA, Frankfurt, Germany, 1980.

[26] E. Riecke, "Die Wasserstoffaufnahme von Eisen bei der Korrosion in neutralen bis schwach sauren Elektrolyten," Werkstoffe und Korrosion, vol. 29, no. 2, pp. 106-112, 1978.

[27] B. Neubert and U. Nürnberger, Untersuchungen der Statischen Kenngrößen und des Dynamischen Tragverhaltens von Spannstählen in Abhängigkeit vom Rostgrad, Schriftenreihe des Deutschen Ausschuss für Stahlbeton, Heft 405, 1990.

[28] G. Rehm, U. Nürnberger, and B. Neubert, "Chlorid korrosion von Stahl in gerissenem Beton," Schriftenreihe Deutscher Ausschuss für Stahlbeton, vol. 390, pp. 43-144, 1988.

[29] C. A. Apostolopoulos, "Mechanical behavior of corroded reinforcing steel bars S500s tempcore under low cycle fatigue," Construction and Building Materials, vol. 21, no. 7, pp.1447-1456, 2007.

[30] A. Braconi, F. Braga, S. Caprili, R. Gigliotti, and W. Salvatore, "Seismic demand on steel reinforcing bars in reinforced concrete frame structures," Bulletin of Earthquake Engineering, vol. 12, no. 6, pp. 2633-2664, 2014.

[31] F. Braga, S. Caprili, R. Gigliotti, and W. Salvatore, "Hardening slip model for reinforcing steel bars," Earthquake and Structures, vol. 9, no. 3, pp. 503-539, 2015.

[32] EN, "Steel for the reinforcement and prestressing of concretetest methods-part 1: reinforcing bars, wire rod and wire," EN ISO 15630-1:2010, 2010.

[33] A. Braconi, F. Braga, S. Caprili, R. Gigliotti, and W. Salvatore, "Influence of low-cycle fatigue and corrosion phenomena on the ductile behaviour of steel reinforcing bars," in Proceedings of the 4th ECCOMAS Thematic Conference on Computational Methods in Structural Dynamics and Earthquake Engineering (COMPDYN '13), Kos Island, Greece, June 2013.

[34] ASTM International, "Operating salt spray (fog) apparatus," ASTM B117-11, ASTM International, West Conshohocken, Pa, USA, 2012.

[35] ISO, "Corrosion tests in artificial atmospheres-salt spray tests," ISO 9227, International Organization for Standardization, 2006.

[36] C. A. Apostolopoulos, S. Demis, and V. G. Papadakis, "Chloride-induced corrosion of steel reinforcement-mechanical performance and pit depth analysis," Construction and Building Materials, vol. 38, pp. 139-146, 2013.

[37] J. A. González, C. Andrade, C. Alonso, and S. Feliu, "Comparison of rates of general corrosion and maximum pitting penetration on concrete embedded steel reinforcement," Cement and Concrete Research, vol. 25, no. 2, pp. 257-264, 1995.

[38] L. Yu, R. François, V. H. Dang, V. L'Hostis, and R. Gagné, "Distribution of corrosion and pitting factor of steel in corroded RC beams," Construction and Building Materials, vol. 95, pp. 384-392, 2015.

[39] K. A. T. Vu and M. G. Stewart, "Predicting the likelihood and extent of reinforced concrete corrosion-induced cracking," Journal of Structural Engineering, vol. 131, no. 11, pp. 1681-1689, 2005.

[40] F. Tang, Z. Lin, G. Chen, and W. Yi, “Three-dimensional corrosion pit measurement and statistical mechanical degradation analysis of deformed steel bars subjected to accelerated corrosion," Construction and Building Materials, vol. 70, pp. 104-117, 2014. 

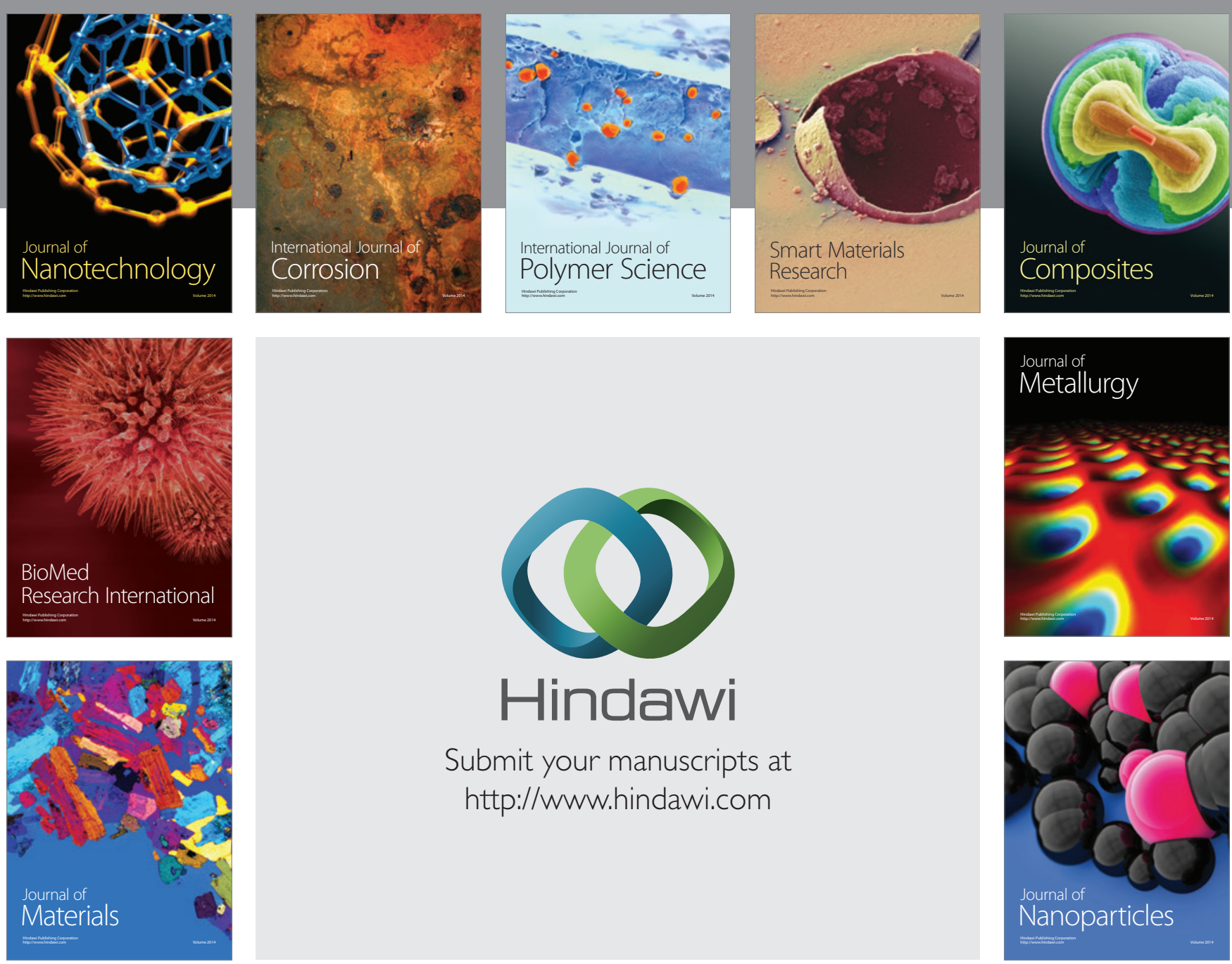

Submit your manuscripts at http://www.hindawi.com
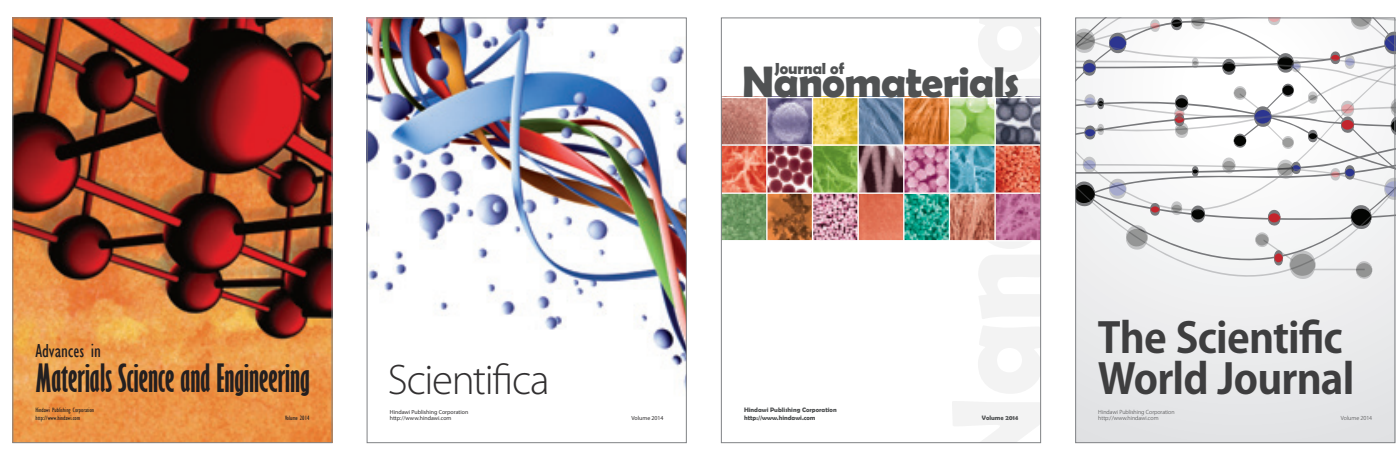

\section{The Scientific World Journal}
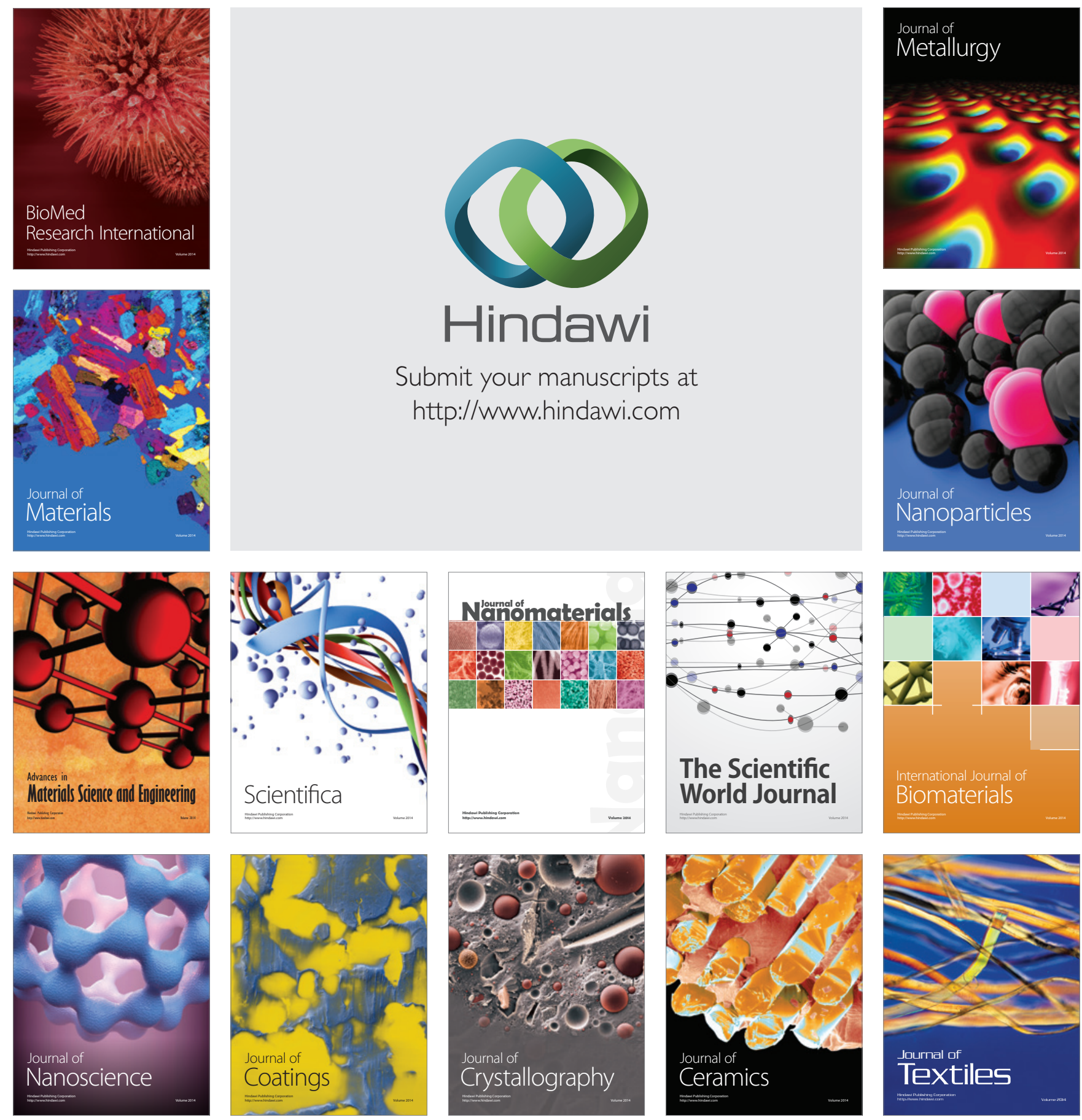